\title{
The Variation of Slat Noise with Mach and Reynolds Numbers
}

\author{
David P. Lockard* and Meelan M. Choudhari ${ }^{\dagger}$ \\ NASA Langley Research Center, Hampton, VA 23681
}

\begin{abstract}
The slat noise from the 30P30 N high-lift system has been computed using a computational fluid dynamics code in conjunction with a Ffowcs Williams-Hawkings solver. By varying the Mach number from 0.13 to 0.25, the noise was found to vary roughly with the 5 th power of the speed. Slight changes in the behavior with directivity angle could easily account for the different speed dependencies reported in the literature. Varying the Reynolds number from 1.4 to 2.4 million resulted in almost no differences, and primarily served to demonstrate the repeatability of the results. However, changing the underlying hybrid Reynolds-averaged-Navier-Stokes/Large-Eddy-Simulation turbulence model significantly altered the mean flow because of changes in the flap separation. However, the general trends observed in both the acoustics and near-field fluctuations were similar for both models.
\end{abstract}

\section{Nomenclature}

$\begin{array}{ll}a & \text { speed of sound } \\ c & \text { stowed chord } \\ C p & \text { coefficient of pressure } \\ c_{s} & \text { slat chord } \\ f & \text { frequency } \\ L_{c} & \text { coherence length scale } \\ M & \text { Mach number, }\left|\mathbf{V}_{o}\right| / a_{o} \\ \text { OASPL } & \text { overall SPL } \\ p & \text { pressure } \\ \text { PSD } & \text { power spectral density } \\ \operatorname{Re}_{c} & \text { Reynolds number, }\left|\mathbf{V}_{o}\right| c / \nu_{o} \\ R_{p p} & \text { spanwise correlation of pressure } \\ \operatorname{rms} & \text { root mean square } \\ S & \text { distance along trajectory of cove shear layer } \\ \mathrm{SPL} & \text { sound pressure level } \\ S t & \text { Strouhal number, } f^{*} c_{s} /\left|\mathbf{V}_{\mathbf{o}}\right| \\ \mathrm{TKE} & \text { turbulence kinetic energy }\end{array}$

$\begin{array}{ll}u, v, w & \text { Cartesian fluid velocity components } \\ U, V, W & \text { time-averaged velocity components } \\ |\mathbf{V}| & \text { magnitude of velocity vector } \\ \left|\mathbf{V}_{2 D}\right| & \text { planar velocity mangitude } \\ x, y, z & \text { Cartesian coordinates }\end{array}$

Greek:

$\rho \quad$ fluid density

$\nu \quad$ kinematic viscosity

$\Delta z \quad$ spanwise distance

Superscript:

' perturbation quantity (e.g. $\rho^{\prime}=\rho-\rho_{\infty}$ )

* dimensional quantity

Subscript:

$\begin{array}{ll}\infty & \text { dimensionless free-stream quantity } \\ o & \text { dimensional free-stream reference quantity } \\ \text { ref } & \text { reference value for velocity scaling }\end{array}$

\section{Introduction}

The non-propulsive (or airframe) sources of aircraft noise include high-lift devices (i.e., leading-edge slat and trailing-edge flaps) and the aircraft undercarriage. The ranking of these sources is configuration dependent; however, both model scale tests ${ }^{1-6}$ and flyover noise measurements ${ }^{7}$ have identified the leading-edge slat as a prominent source of airframe noise during aircraft approach. The slat noise spectrum is typically broadband, but may include one or more narrower peaks associated with aerodynamic and/or aeroacoustic resonances. Previous measurements indicate that the broadband spectrum has a maximum near Strouhal numbers between 1 to 3 (where the Strouhal number $=f^{*} c_{s} /\left|\mathbf{V}_{o}\right|$ is based on the free-stream velocity $\left|\mathbf{V}_{o}\right|$ and slat chord $c_{s}$ ), and exhibits a peak in the directivity in the lower aft quadrant at the corresponding frequency. ${ }^{8}$ The overall sound pressure level (OASPL) for slat noise sources has been noted to scale with $M^{4.5}$ by Dobrzynksi ${ }^{8}$ and $M^{5}$ by Guo, ${ }^{9,10}$ where $M$ denotes the free-stream or flight Mach number. Mendoza ${ }^{6}$ found that the overall sound pressure level scaled with $M^{5}$, but with something between $M^{4}$ and $M^{5}$ in the range of mid to high frequencies. However, as discussed in Refs. 8 and 10, the physical mechanisms underlying the observed characteristics of slat noise have not been fully explained as yet.

An essential ingredient to developing physics-based predictions of airframe noise involves synergistic combinations of experiments and numerical simulations for subcomponents. Recent studies of this type have provided a number of useful physical insights into the noise source mechanisms that are responsible for the dominant features of the measured

*Aerospace Technologist, Computational AeroSciences Branch, Mail Stop 128, Senior Member, AIAA

${ }^{\dagger}$ Aerospace Technologist, Computational AeroSciences Branch, Mail Stop 128, Associate Fellow, AIAA 
slat- and flap-noise spectra. Specifically, the high-frequency spectral hump in the slat noise measurements at NASA ${ }^{2,5}$ has been attributed to vortex shedding from a finite thickness slat trailing edge. ${ }^{11,12}$ The broadband component of slat noise at lower frequencies has been linked with the interaction between unsteady vortical structures in the slat cove region and the adjacent features of the high-lift geometry (viz., the slat trailing edge and the gap region between the slat and the main element). ${ }^{13-15}$ The two-dimensional (2-D) computations of this type helped clarify the cause-effect relationships between the near-field flow structures and the far-field noise; however, a further assessment of these computations ${ }^{16}$ indicated excessively energetic vortical structures in comparison with the PIV measurements. ${ }^{17}$ Three-dimensional (3D) computations over a narrow portion of the model $\operatorname{span}^{18}$ led to significant improvement in that regard, yielding a favorable comparison with the PIV measurements. ${ }^{17}$ The importance of 3-D fluctuations in determining the unsteady dynamics within the cove region has also been confirmed via computations for other high-lift configurations and using alternative numerical algorithms. ${ }^{19,20}$

The acoustic sources in the slat cove have been investigated experimentally ${ }^{17}$ using the $30 \mathrm{P} / 30 \mathrm{~N}$ model. The $30 \mathrm{P} / 30 \mathrm{~N}$ model tested in the Basic Aerodynamic Research Tunnel (BART) at NASA Langley Research Center represents a generic, three-element, zero-sweep high-lift configuration with slat and flap deflections of 30 degrees each. The slat chord and flap chord of the model are equal to $15 \%$ and $30 \%$, respectively, of the stowed chord of 18 in $(0.457 \mathrm{~m})$. For the approach configuration, the slat gap is $2.95 \%$; the flap gap is $1.27 \%$; and the slat and flap overhang settings are equal to $-2.95 \%$ and $0.25 \%$ of the stowed chord, respectively. Reference 21 provides a definition of these rigging parameters. At the test Mach number of $M=0.17$, the Reynolds number, $\operatorname{Re}_{c}$, based on the stowed chord of the BART model, corresponds to 1.71 million. While this Reynolds number is substantially lower in comparison with full-scale applications, the BART experiment is still suitable for validating numerical predictions of the slat cove noise sources as described in Ref. 18. The BART measurements ${ }^{17}$ consist of steady surface pressure measurements, plus extensive 2-D particle image velocimetry (PIV) data within the mid-span plane of the model.

The effect of the spanwise extent of the computational domain was investigated by Lockard and Choudhari ${ }^{22}$ by increasing the span from 1" (37.3\% of the slat chord as used in Ref. 18) to 6" (226\% of the slat chord or $15 \%$ of the model span) while maintaining the same spanwise resolution. The simulations with the longer span indicated that the spanwise surface pressure correlations do not become smaller than 0.05 until around 2" (74.6\% of the slat chord). The longer span also enabled predictions of the far-field noise without excessive assumptions about the near-field spanwise behavior. However, the spanwise correlation length of the acoustic signals was found to be on the order of a slat chord, so a much longer span than even $226 \% c_{s}$ would be needed to adequately propagate noise to the far-field at frequencies near the peak in the broadband signal. Nonetheless, the near-field unsteadiness that gives rise to the noise can be adequately modeled with a 2" span, allowing the shorter span to be used in parametric studies examining the source mechanism.

Although the slat geometry is basically 2-D, most modern aircraft have swept wings which will produce a spanwise flow. Imamura et $\mathrm{al}^{23}$ performed simulations of both swept and unswept wing configurations, but their results for the near-field unsteadiness were inconclusive as to the effect of the cross flow because the observed differences were deemed to be within their uncertainty. Lockard and Choudhari ${ }^{24}$ simulated the $30 \mathrm{P} / 30 \mathrm{~N}$ with two different freestream flows that included an imposed spanwise velocity. Their results indicated that the fluctuations and noise scaled primarily with the velocity normal to the leading edge rather than the total velocity. However, their simulations varied both the Mach and Reynolds numbers simultaneously in an attempt to keep the same boundary layer characteristics in the cross flow cases. Hence, the independent effects of the Mach number, Reynolds number, and cross flow could not be determined.

The current effort seeks to computationally examine the effect of the Mach and Reynolds numbers on the noise radiated from the $30 \mathrm{P} / 30 \mathrm{~N}$ configuration. Isolating these effects should help clarify the influence of sweep as observed in previous simulations. ${ }^{24}$ Additionally, in experiments ${ }^{5}$ conducted in the Low Turbulence Pressure Tunnel at NASA Langley, the noise from a 3 element high-lift system was examined for Reynolds numbers from 3.6 to 19 million. The noise was found to be relatively insensitive to Reynolds number variations above 7.2 million. The current simulations seek to examine the influence of the Reynolds number within the framework of simulations, and, hopefully, establish the relevance of low-Reynolds number slat aeroacoustic experiments. Furthermore, isolating the independent effects of $M$ and $\mathrm{Re}_{c}$ will be useful in guiding the development of simplified models for the noise and lay the foundation for future examinations of the effect of other significant parameters such as the angle of attack, slat deflection, slat gap, and noise reduction devices.

The simulations use an extruded 2-D geometry without cross flow. Table I lists the parameters for the 6 cases that have been completed. The velocities in the table and this paper are nondimensionalized by the free-stream speed of sound, and, therefore are equivalent to Mach numbers. For all of these cases, the freestream vertical and spanwise velocities are zero, so $\left|\mathbf{V}_{\infty}\right|=U_{\infty}$. The Mach number has been varied from 0.13 to 0.25 at the baseline Reynolds number of 1.71 million based on the stowed chord, and a Reynolds number sweep was conducted from 1.209 to 2.418 million at the baseline Mach number of 0.17 . The Reynolds numbers correspond with those used in reference 24 in the examination of cross flow. 
Table 1. Case definitions.

\begin{tabular}{|l|c|c|}
\hline & $\left|\mathbf{V}_{\infty}\right|$ & $\operatorname{Re}_{c} \times 10^{-6}$ \\
\hline \hline Case 1 & 0.13 & 1.71 \\
\hline Case 2 & 0.17 & 1.71 \\
\hline Case 3 & 0.21 & 1.71 \\
\hline Case 4 & 0.25 & 1.71 \\
\hline Case 5 & 0.17 & 1.209 \\
\hline Case 6 & 0.17 & 2.418 \\
\hline
\end{tabular}

\section{Computational Simulations}

The computational procedure closely follows that used during the simulations in Refs. 18, 22, and 24. Version 6 of the CFL3D ${ }^{25}$ flow solver developed at NASA Langley Research Center is used to solve the 3-D, time-dependent, Navier-Stokes equations using a finite-volume formulation; the full viscous fluxes in all three grid coordinates were retained during the present simulations. A hybrid approach is used where the RANS equations are solved in regions where the grid is insufficient to resolve the unsteady turbulent eddies, such as in boundary layers around solid bodies, and an implicit large eddy simulation (LES) is performed in regions where the grid can resolve the eddy dynamics. The simulations used a third-order upwind scheme with flux-difference splitting, which has been shown to provide second order spatial accuracy in previous applications of CFL3D. ${ }^{25}$ Based on the spanwise correlation results of Ref. 22, a spanwise extent of 2" (74.6\% of the slat chord) is used in the simulations.

\section{II.A. Configurations and Grids}

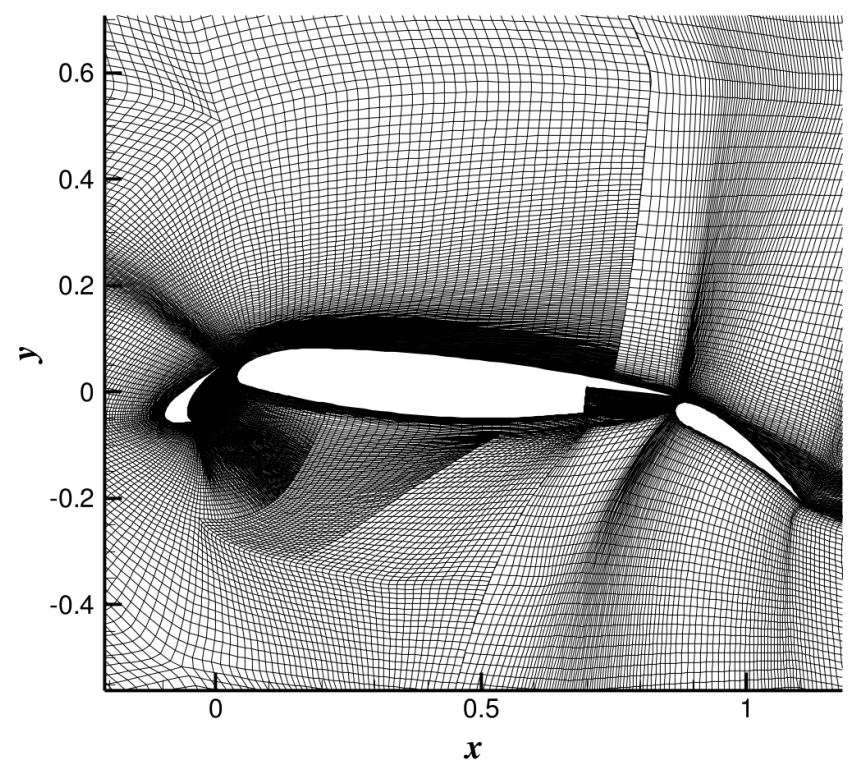

Figure 1. Planar view of grid (every other point).

The $30 \mathrm{P} / 30 \mathrm{~N}^{21}$ high-lift system was simulated in free air without any of the wind-tunnel walls. The trailing edge of each of the three elements has a finite thickness. However, following the approach taken in Ref. 22 for computational efficiency, all of the trailing edges (including the cusp or first edge of the slat) were artificially sharpened while preserving the camber of the respective sections. The investigated configuration corresponds to $4^{\circ}$ angle of attack in BART, ${ }^{17}$ which approximates the mean slat loading for a free-flight configuration at $5.5^{\circ}$ angle of attack. The block structured, $x-y$ planar grid shown in Fig. 1 contained a total of 563,741 points in 77 blocks. Care was taken so that the first point off the solid surfaces was at $y^{+}<1$. To generate the 3-D grids, the planar mesh was replicated along the span over a distance of 0.746 slat chords using 129 points for a total grid point count of 62 million. Most of the block interfaces are point- 
matched with a one-to-one correspondence from each side. However, patched interfaces, where the grid is coarsened going from one block to its neighbor, were employed but restricted to regions away from the slat. The planar grid and spanwise grid spacing are identical to that used in Ref. 22 and 24, and they are based on the grid resolution studies in Ref. 18. The grid was developed for a nominal Reynolds number of 1.71 million, but still provides good resolution with $y^{+}<1$ for a $\operatorname{Re}_{c}$ of 2.4 million as examined in Ref. 24 for cases with cross flow. Calculations with even higher $\operatorname{Re}_{c}$ up to 12 million are ongoing, but the grid would need to be modified to account for the thinner boundary layers at even higher $\operatorname{Re}_{c}$.

Characteristic boundary conditions were used along the far-field boundaries in the $x-y$ plane, except for extrapolation from the interior at the downstream boundary. The circular outer boundary was located 12 airfoil chords from a point in the slat cove. Periodic boundary conditions were used across the spanwise boundaries of the computational domain. No attempt was made to resolve the end effects associated with the presence of tunnel side walls in the experiments. No-slip conditions were imposed at the solid surfaces, along with an adiabatic wall thermal boundary condition.

The two-equation Shear Stress Transport (SST) model of Menter ${ }^{26}$ was used to capture the mean flow behavior of the unresolved scales of motion in regions away from the slat cove region, whereas the turbulence production term in the turbulence transport equations was switched off within the cove region ${ }^{18}$ to eliminate the excessive diffusive effects of the turbulence model on the resolved unsteady flow structures. The designation SST QL refers to the combination of the SST turbulence model and a Quasi-Laminar cove. Due to a lack of experimental transition data along the solid surfaces, as well as to maintain consistency with the previous simulations, ${ }^{14-16}$ the flow within the Reynolds-Averaged Navier Stokes (RANS) regions was treated as fully turbulent, allowing the boundary layer transition locations along all three elements to be determined by the SST turbulence model. Computations have also been performed using a modified version of the Delayed Detached Eddy Simulation ${ }^{27}$ (DDES) methodology based on the Spalart-Allmaras ${ }^{28}$ turbulence model. The DDES approach automatically switches between RANS and LES modes based on the proximity to solid surfaces, the local flowfield, and the grid resolution. The modified version, MDDES, ${ }^{29}$ affects both the production and destruction terms in the turbulence model, resulting in lower eddy-viscosity values in LES regions.

CFL3D employs a dual-time-stepping algorithm with subiterations used to converge the solution within each time step. Fifteen subiterations were used per time step to reduce the residual by a minimum of three orders of magnitude. The time step was $d t^{*} a_{o} / c=0.0016464$ or $d t^{*}\left|\mathbf{V}_{\mathbf{o}}\right| / c=0.00028$. The corresponding convective scale for a particle traveling with the flow to traverse the stowed chord of the airfoil is 3573 time steps. The time step used in the current simulations is larger than those used in some earlier studies of the $30 \mathrm{P} / 30 \mathrm{~N}$ configuration ${ }^{16,18}$ because the trailing-edges have been sharpened to avoid having to resolve the small trailing-edge thickness that would have enabled the simulations to capture any high-frequency vortex shedding behind the edges. Based on the time-step study performed in Ref. 22, the step size used in the current simulations should be sufficient to resolve the broadband component of the slat fluctuations which is the focus of the present study.

The simulation procedure includes several steps. First, a steady-state computation was used to set up the basic mean flow, followed by an unsteady calculation with random suction and blowing applied to different spanwise and azimuthal sections of the slat in order to accelerate the onset of 3-D, unsteady flow structures. The forcing did not exceed 3\% of the freestream velocity. The forcing was turned off after significant unsteadiness was observed, typically a few hundred time steps into the unsteady calculation. The simulation was then run for at least 30,000 time steps to allow the transient flow field to wash out before collecting time records. After this phase, well-resolved, unsteady structures develop in the slat cove region. There is also some unsteadiness associated with a separated region on the flap. The grid is too coarse to resolve the unsteady flow around the flap, and these fluctuations eventually settle down to levels that do not significantly impact the slat cove region. In the real flow, the oscillations in the flap separated region are probably persistent and much stronger, but the purpose of the current study is to isolate the slat cove dynamics. Therefore, the observed damping behavior in the flap region is actually intended and advantageous. Averaged flow quantities were produced by timeaveraging over 39,000 time steps. To increase the number of averages, a second averaging process was performed in the spanwise direction. Although shear layers can exhibit inhomogeneous spanwise behavior, assuming spanwise homogeneity of the flow statistics is consistent with the observations of this particular flowfield. 


\section{Results: Variation with Mach Number}

The coefficient of pressure, $C p=2\left(p^{*}-p_{o}\right) /\left(\rho_{o}\left|\mathbf{V}_{o}\right|^{2}\right)$, on the high-lift system is presented in Fig. 2. The results from the four calculations with different Mach numbers are included. The data was generated by averaging over time, then averaging over the span by assuming the flow is basically homogeneous in that direction. The slight jump on the pressure side at $x^{*} / c=0.7$ is caused by the geometric discontinuity where the flap cove begins. The $C p$ distributions for the four Mach numbers are slightly different, with $\left|\mathbf{V}_{\infty}\right|=0.13$ producing the least lift. The trend is monotonic suggesting that the effect is physical and not just an artifact of computational uncertainty. The flap separation changes slightly with Mach number affecting the overall lift distribution. Additionally, compressibility may be playing some role in the changes, especially in the vicinity of the leading edge of the main element where the local Mach number is around 2.5 times greater than the freestream velocity. In the calculations in Ref. 22, the total lift on the high-lift system drifted by $2 \%$ during the calculation because the separation on the flap was very slow to establish a quasi-steady state. The drift was minimized in the current simulations by running the cases longer before starting sampling. To further reduce the effect of any drift in the fluctuating pressure levels, the root-mean-square (rms) levels of $C p^{\prime}$ were calculated over segments of 3000 time steps. Over each of these segments, the perturbations were calculated relative to the short-time mean for the segment. A subsequent average was performed over rms levels from all of these segments. A comparison of the calculated $C p_{r m s}^{\prime}$ is shown in Fig. 3. Near the reattachment point in the slat cove at $x^{*} / c=0.005$, the $C p_{r m s}^{\prime}$ reaches a maximum. The four curves do not collapse in that region, but the agreement is reasonable otherwise. Normalization of $C p^{\prime}$ by $\left|\mathbf{V}_{o}\right|^{2.2}$ produces an excellent collapse in the region of peak pressure fluctuations over the slat pressure surface, except for $\left|\mathbf{V}_{\infty}\right|=0.25$ being very slightly below the other cases. Although this indicates that overall $p^{2} \sim\left|\mathbf{V}_{o}\right|^{4.4}$, this does not mean that the fluctuations at each frequency are behaving in this manner.

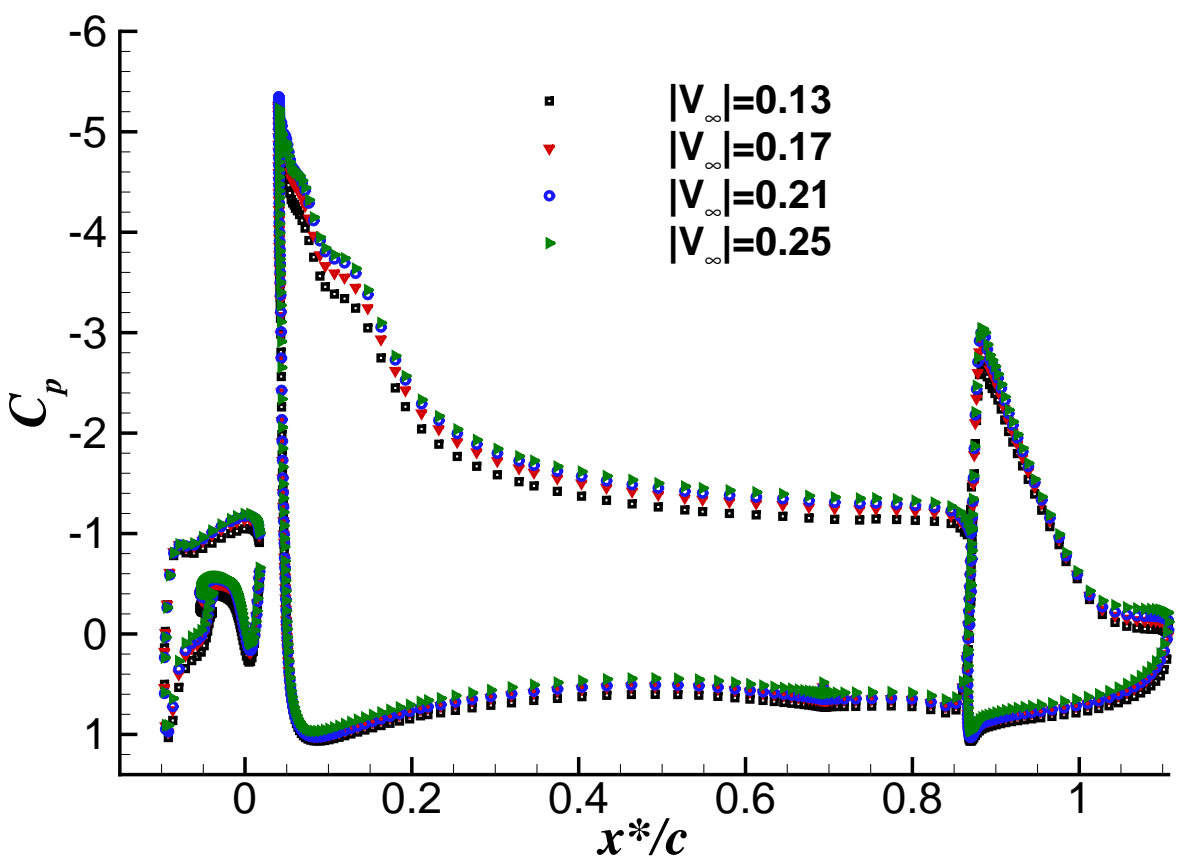

Figure 2. Coefficient of pressure on the airfoil.

The magnitude of the planar velocity $\left|\mathbf{V}_{2 D}^{*}\right|$, nondimensionalized by $\left|\mathbf{V}_{\mathbf{o}}\right|$, is compared in Fig. 4. The velocity distributions are quite similar for all three computations. The trajectory of the shear layer, shown as the purple line, and the reattachment point on the lower surface of the slat are nearly identical in all cases. However, the 3-D turbulence kinetic energy (TKE), $\left.\frac{1}{2}\left(<u^{\prime} u^{\prime}\right\rangle+\left\langle v^{\prime} v^{\prime}\right\rangle+\left\langle w^{\prime} w^{\prime}\right\rangle\right)$, normalized by the square of the free-stream velocity, $\left|\mathbf{V}_{\mathbf{o}}\right|^{2}$, does reveal some differences as seen in Fig. 5. The thin region of high 3-D TKE near the reattachment point and extending to the trailing edge is more pronounced as the Mach number increases until plateauing between the two highest Mach numbers. The spanwise fluctuations are primarily responsible for the high TKE in this region. Just below this region is another, larger area of enhanced TKE where the vertical velocity fluctuations peak. The elevated TKE levels are caused by instabilities in the cove shear layer being rapidly distorted as they approach the underside of the slat. Some other differences between the four cases are evident such as the region of low TKE in the cove (indicated by the blue regions) being more pronounced at the lower Mach numbers. 


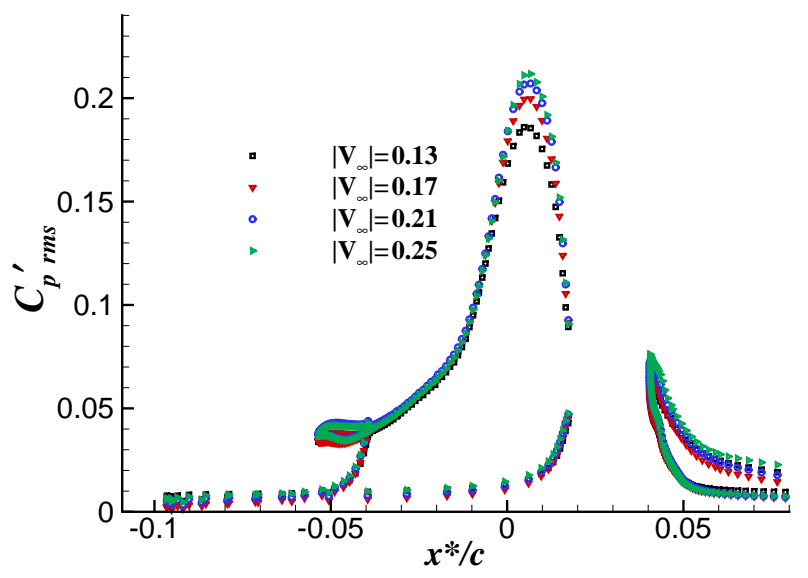

(a) Normalized by $\left|\mathbf{V}_{o}\right|^{2}$

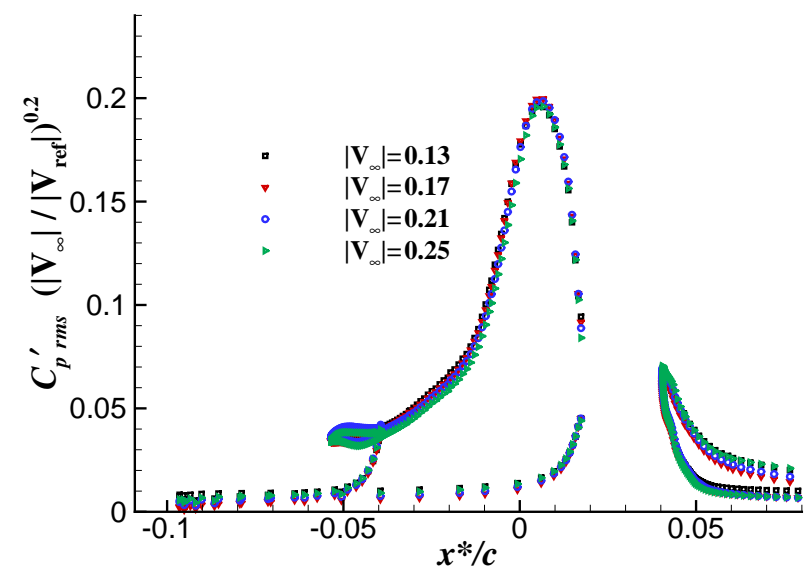

(b) Normalized by $\left|\mathbf{V}_{o}\right|^{2.2}$

Figure 3. Fluctuating $C p^{\prime}$ on the slat.

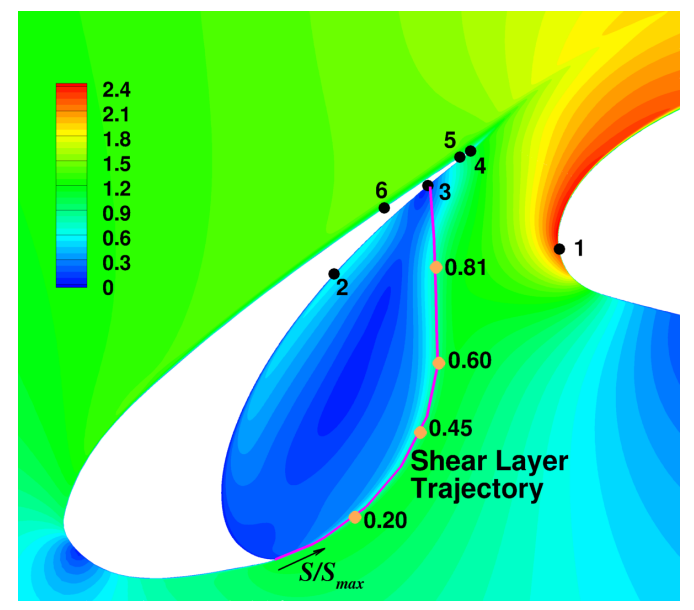

(a) $\left|\mathbf{V}_{\infty}\right|=0.12$

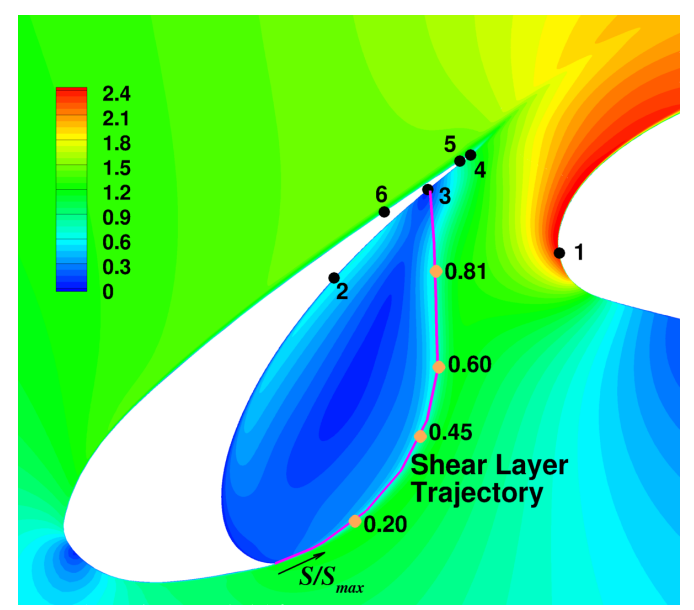

(c) $\left|\mathbf{V}_{\infty}\right|=0.21$

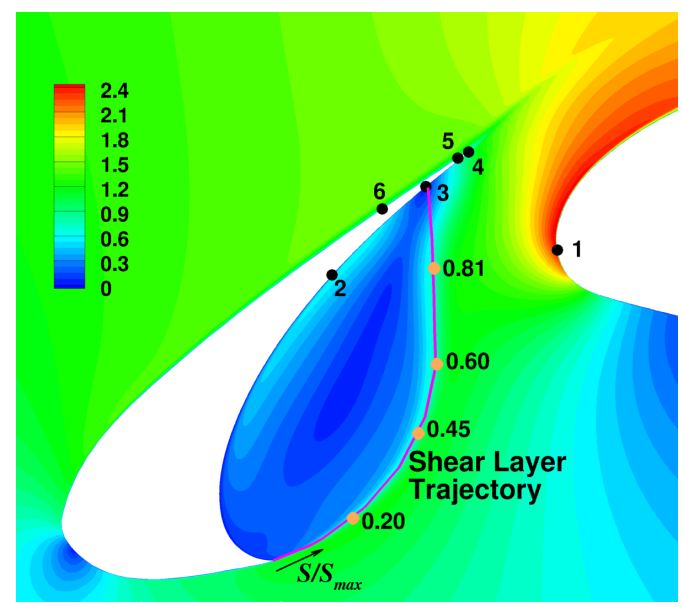

(b) $\left|\mathbf{V}_{\infty}\right|=0.17$

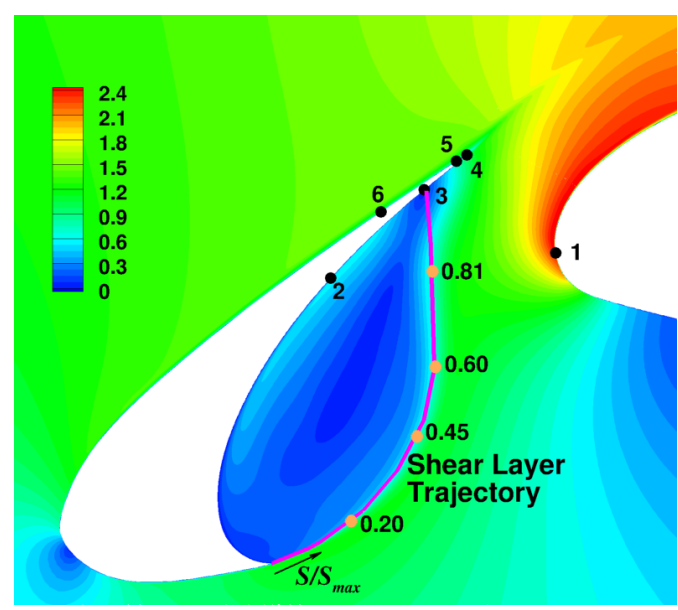

(d) $\left|\mathbf{V}_{\infty}\right|=0.25$

Figure 4. Magnitude of the planar velocity, $\left|\mathbf{V}_{2 D}^{*}\right| /\left|\mathbf{V}_{\mathbf{o}}\right|$, around the slat averaged both temporally and in the spanwise direction. $S$ is the distance along the shear layer trajectory, and $S / S_{\max }=\mathbf{0 . 2 1}, \mathbf{0 . 4 5 , 0 . 6 0 , 0 . 8 2}$ correspond to four points in the shear layer that will be examined. The surface pressure at the points numbered 1 to 6 will also be examined. 


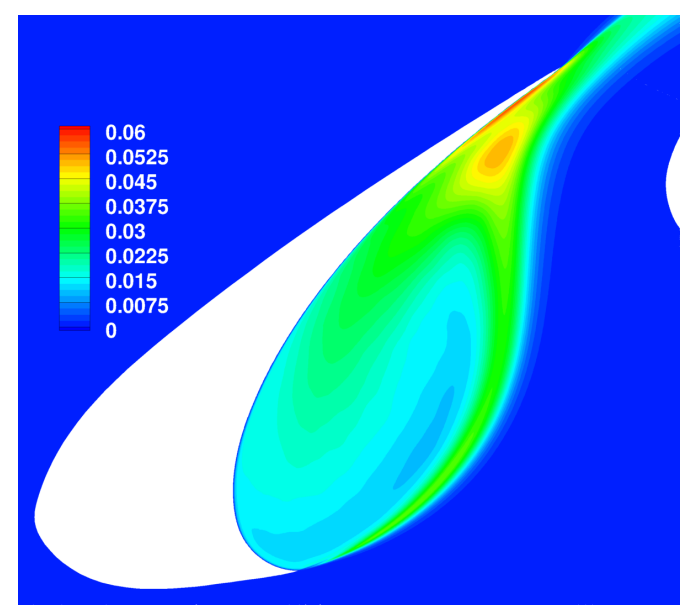

(a) $\left|\mathbf{V}_{\infty}\right|=0.13$

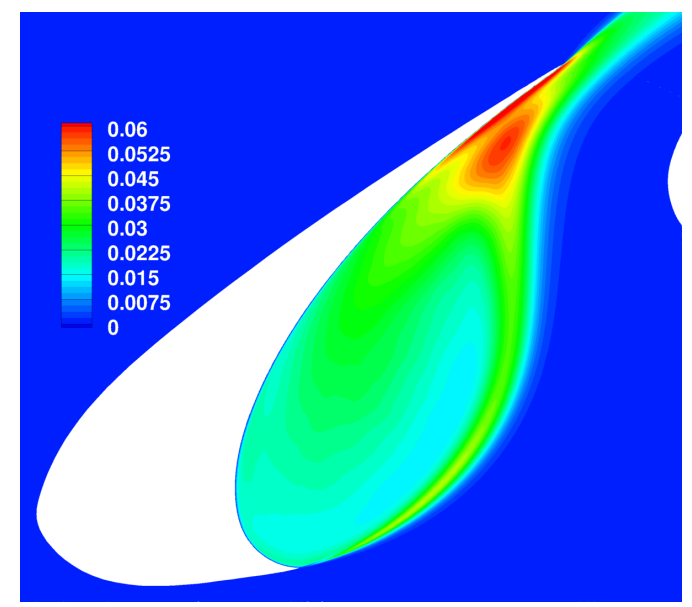

(c) $\left|\mathbf{V}_{\infty}\right|=0.21$

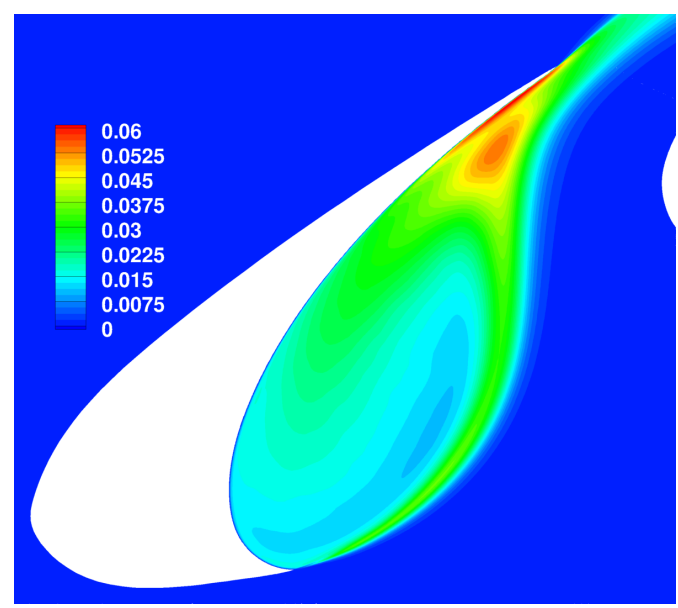

(b) $\left|\mathbf{V}_{\infty}\right|=0.17$

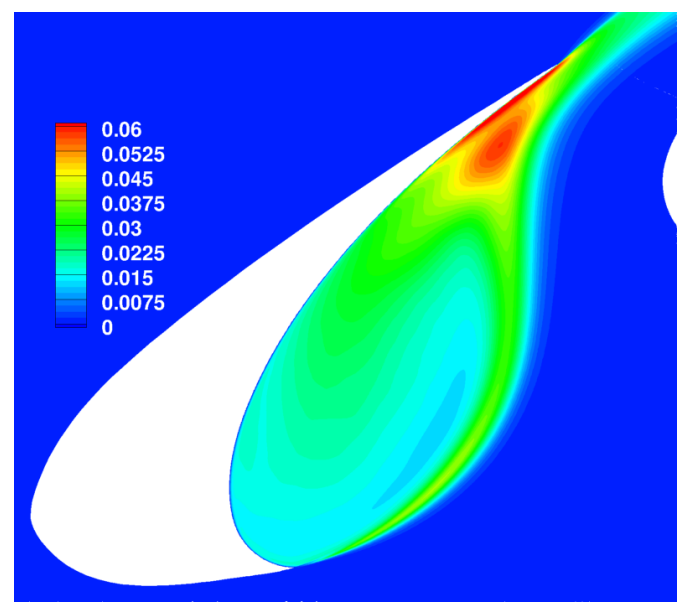

(d) $\left|\mathbf{V}_{\infty}\right|=0.25$

Figure 5. 3-D Turbulence kinetic energy normalized by $\left|V_{o}\right|^{2}$ around the slat averaged both temporally and in the spanwise direction.

The power spectral density (PSD) of the surface pressure at the 6 points identified in Fig. 4 are presented in Fig. 6 . The amplitude has been adjusted assuming $p^{\prime} \sim\left|\mathbf{V}_{\infty}\right|^{2}$ as this produced a reasonable collapse of the rms data. However, as demonstrated in Ref. 24, the important parameter is actually the velocity normal to the leading edge, $U_{\infty}$. In the current calculations $\left|\mathbf{V}_{\infty}\right|=U_{\infty}$, so either velocity could be used. Nonetheless, using $U_{\infty}$ emphasizes what parameter is truly important and will be used in the remainder of the paper. The reference velocity that each of the 4 cases with different Mach numbers will be adjusted to is $U_{\text {ref }}=0.17$. The power spectral density is plotted against the Strouhal number, $S t=f^{*} c_{s} / U_{o}$, based on the free-stream velocity $U_{o}$, and the slat chord, $c_{s}$. Except for points 2 and 6, the scaling does a good job of collapsing the data. Point 2 is within the recirculation region which experiences a high degree of intermittency, so the uncertainty in the statistics is likely to be high. Hence, disagreement there is not unexpected. In general, the results for the higher Mach numbers are in better agreement with each other than with the $\left|\mathbf{V}_{\infty}\right|=0.13$ case. Overall, the amplitude and velocity scaling collapses the data quite well. Furthermore, at point 6 on the upper surface of the slat, all of the cases exhibit spectral peaks that also collapse relatively well using the Strouhal scaling. Nonetheless, at low frequency, the $\left|\mathbf{V}_{\infty}\right|=0.13$ case behaves differently from the other cases.

The spanwise correlation of the pressure, $R_{p p}$, near the reattachment point designated as point 3 in Fig. 4 is shown in Fig. 7(a). The spanwise coordinate is $z$, and the spanwise distance between two grid points with the same values of $x$ and $y$ is given by $\Delta z$. This spanwise distance is normalized by $c_{s}$ in the figure. For each $\Delta z^{*} / c_{s}$, the average value of the correlation is calculated for all grid point combinations with this separation distance. Because of the periodic boundary conditions, the correlation can only be computed for spanwise separations up to half the length of the computational span. The spanwise correlation appears to be relatively insensitive to Mach number. All of the curves exhibit a similar falloff with spanwise separation. Furthermore, the coherence at individual frequencies is also relatively similar between 


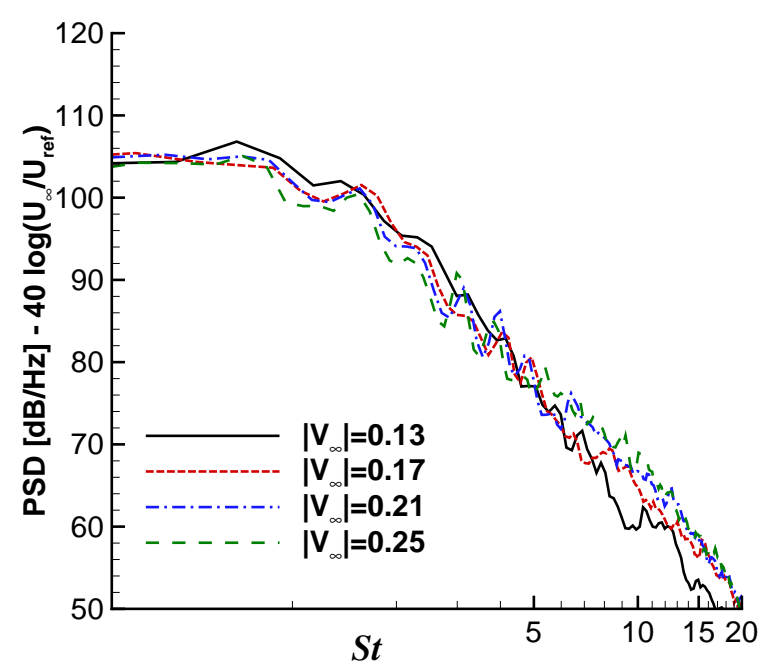

(a) Point 1

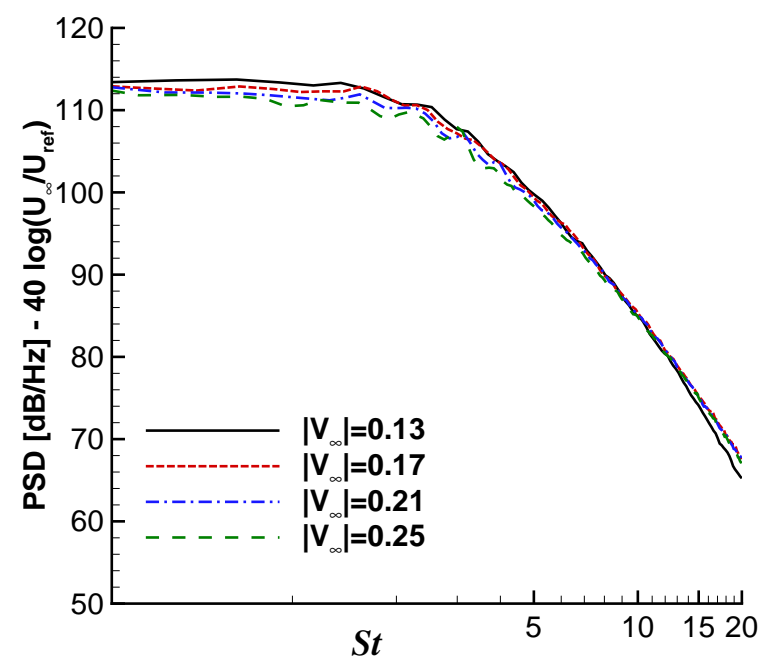

(c) Point 3

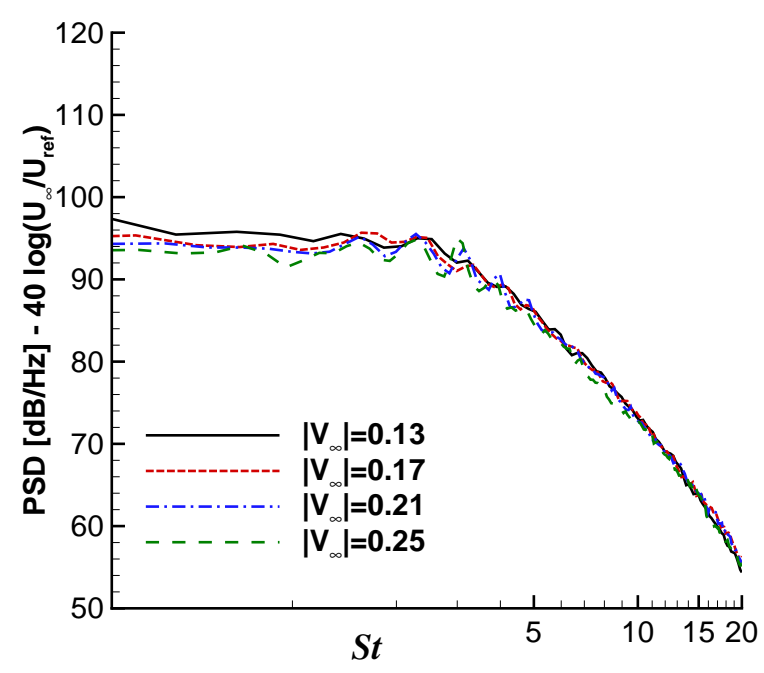

(e) Point 5

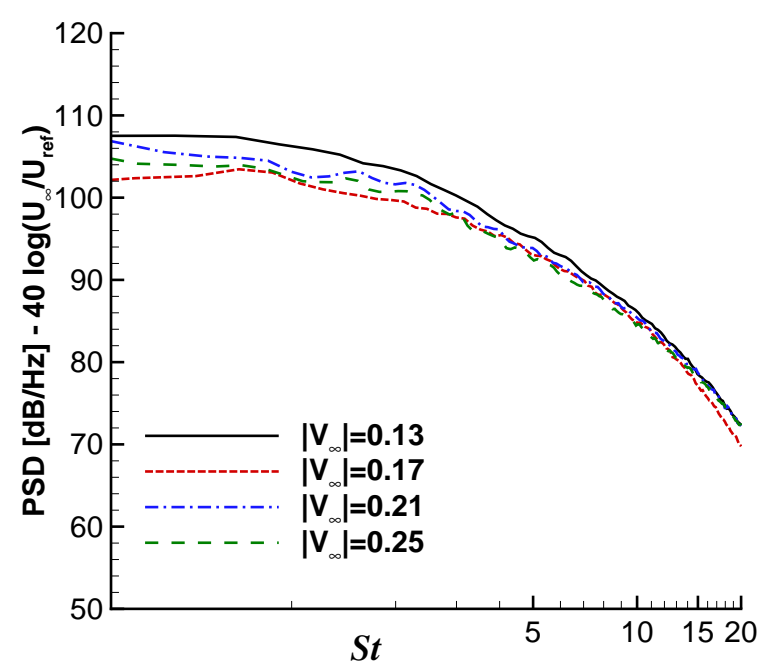

(b) Point 2

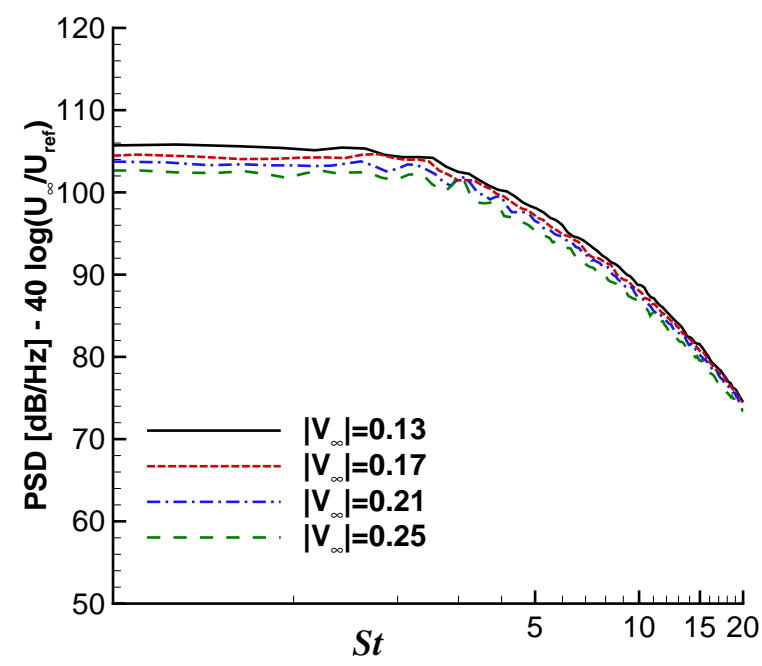

(d) Point 4

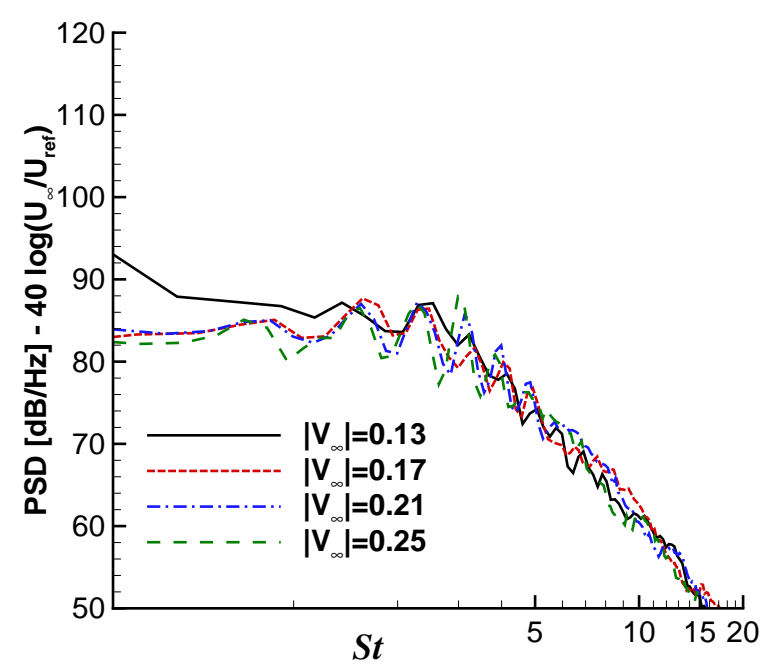

(f) Point 6

Figure 6. Power spectral density versus Strouhal number at the 6 points in Fig. 4. The reference velocity $U_{\text {ref }}=0.17$. 
the four cases. As shown in Ref. 22, the coherence at any frequency can be reasonably approximated by a Gaussian

$$
\gamma^{2}\left(f^{*}\right)=\exp \left[-\left(\frac{\Delta z^{*}}{L_{c}\left(f^{*}\right)}\right)^{2}\right]
$$

which allows the coherence information to be presented in terms of the coherence length scale $L_{c}\left(f^{*}\right)$. The parameter $L_{c}$ is determined for each frequency using a least-squares fit of the data. The coherence length normalized by the slat chord for point 3 is presented in Fig. 7(b). Although the coherence length varies between the cases at the peaks, the overall shape and trends are similar.

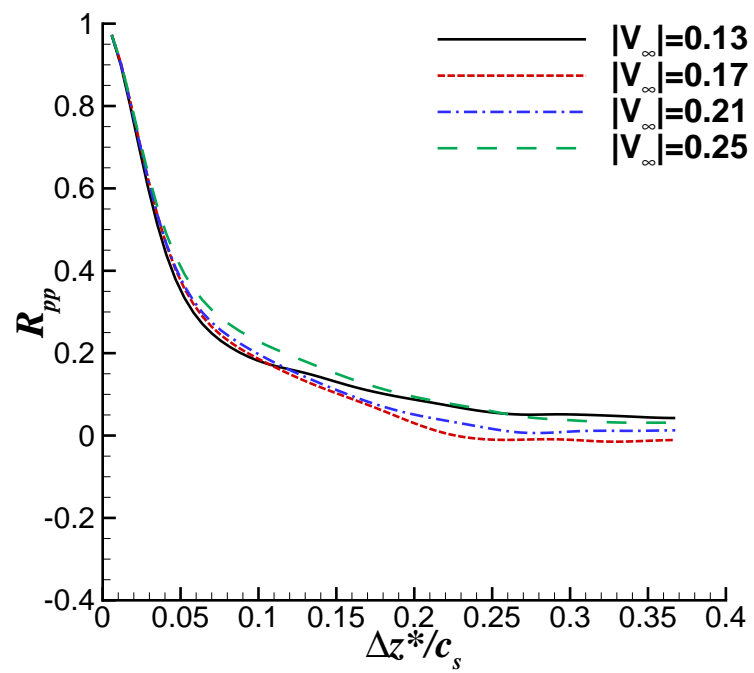

(a) Spanwise Correlation

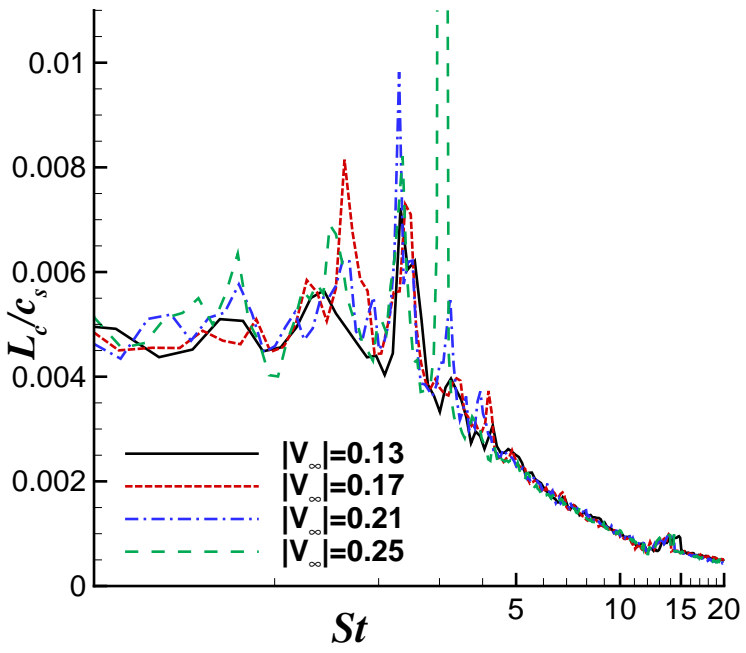

(b) Spanwise Coherence Length

Figure 7. Spanwise correlation and coherence length of $p$ at point 3 in Fig. 4.

The velocity fluctuations in the cove at 4 selected points along the trajectory of the slat cove shear layer are investigated in Figs. 8 and 9. The distance along the trajectory, $S$, has been normalized by the total distance from the cusp to the reattachment point, $S_{\max }$. The power spectral densities have been scaled to the $U_{\infty}=0.17$ case by assuming $u^{\prime} \sim U_{\infty}$ and plotted against the Strouhal number. The range used for the Strouhal number in these plots has been expanded to capture the high-frequency peaks associated with instabilities in the thin shear layer near the cusp. The migration of the peak to lower frequencies as the shear layer spreads is much more apparent in the $u$ velocity than in $v$. At points 2 through 4, the shear layer trajectory is nearly vertical, and, therefore, the PSD of the $v^{\prime}$ signal is much larger than that of the $u^{\prime}$ fluctuations. The cases collapse well using the hydrodynamic scaling, indicating that the mixing layer spreading rates are relatively unaffected by the Mach number variation. However, the intensity of the fluctuations appears to be slightly less than the assumed $u^{\prime} \sim U_{\infty}$, especially for points further along the shear layer. 


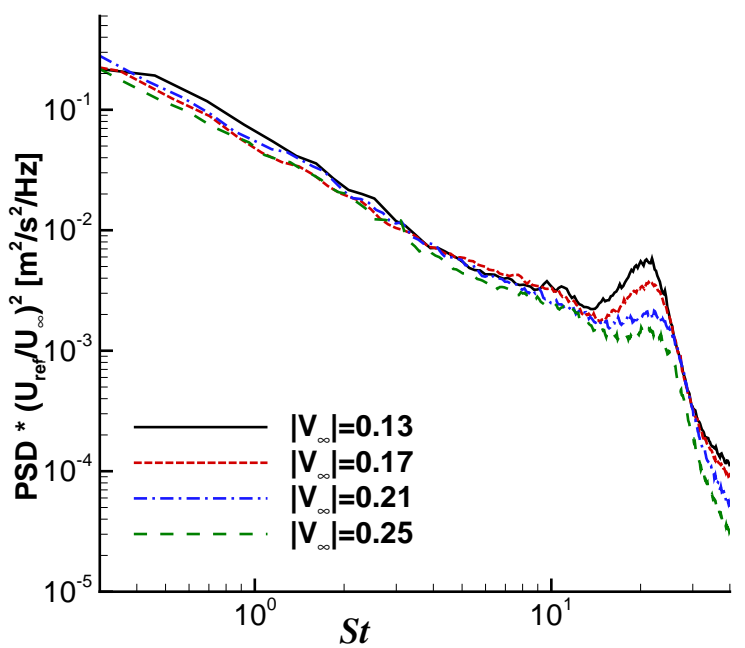

(a) $S / S_{\max }=0.20$

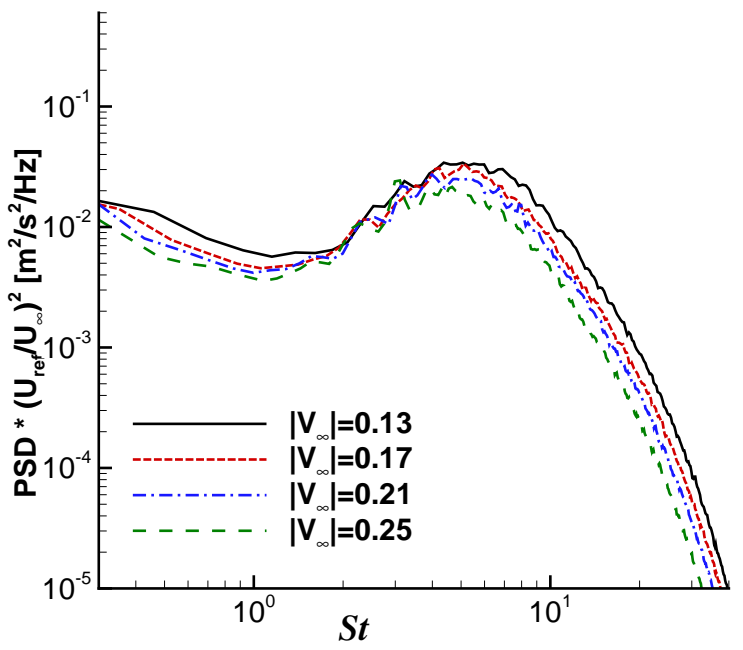

(c) $S / S_{\max }=0.60$

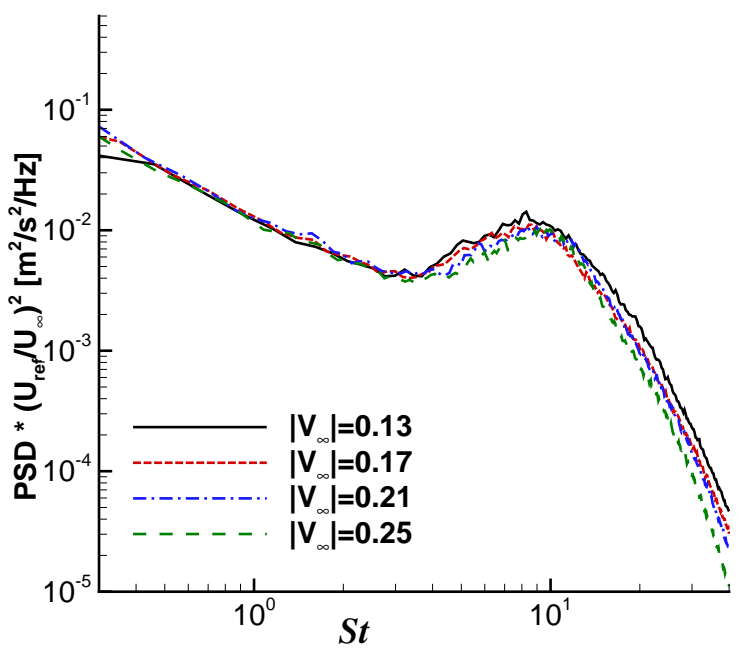

(b) $S / S_{\max }=0.45$

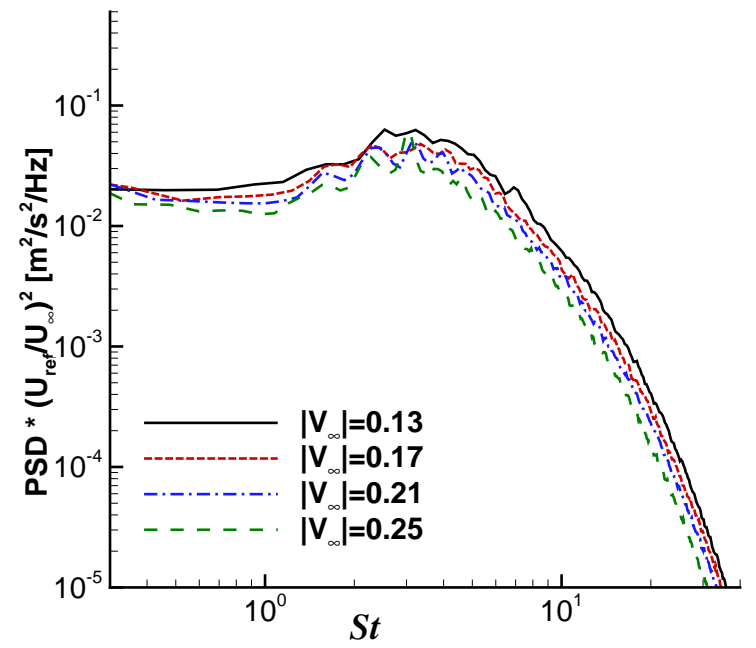

(d) $S / S_{\max }=0.81$

Figure 8. Power spectral density of the $u$ velocities versus Strouhal number at 4 locations defined by $S / S_{\max }$ along the trajectory of the slat cove shear layer shown in Fig. 4. The reference velocity $U_{\text {ref }}=0.17$. 


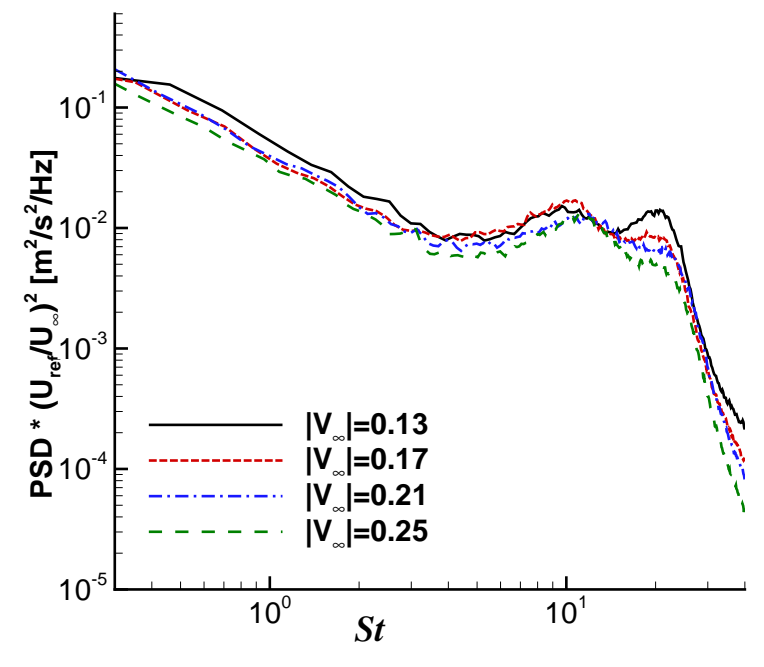

(a) $S / S_{\max }=0.20$

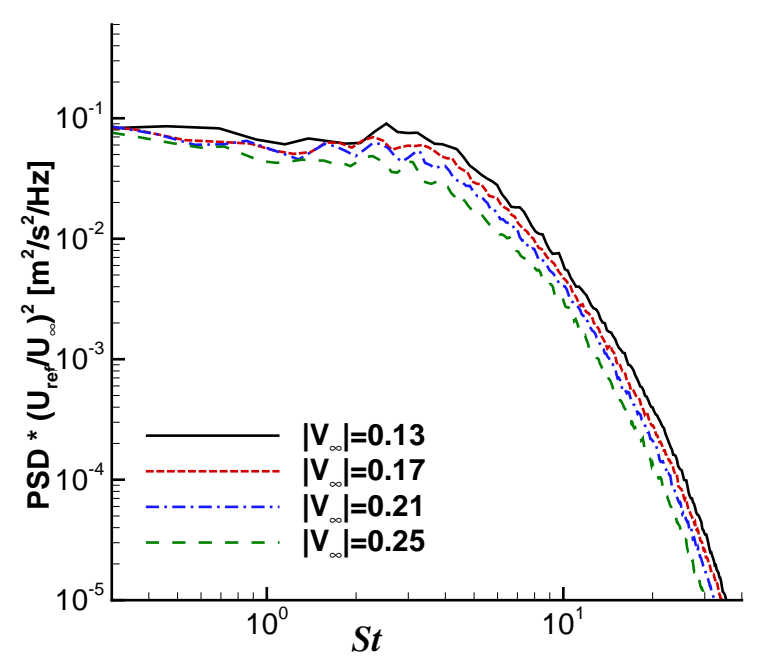

(c) $S / S_{\max }=0.60$

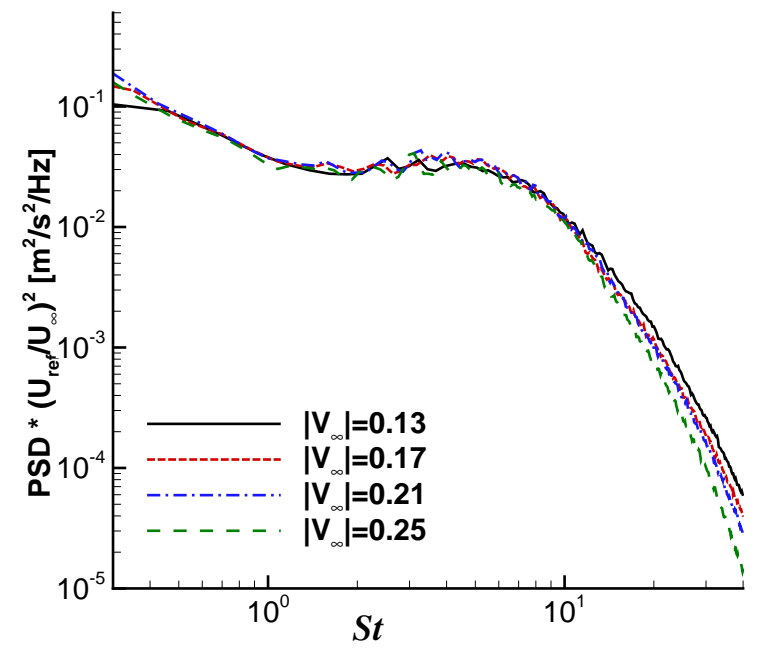

(b) $S / S_{\max }=0.45$

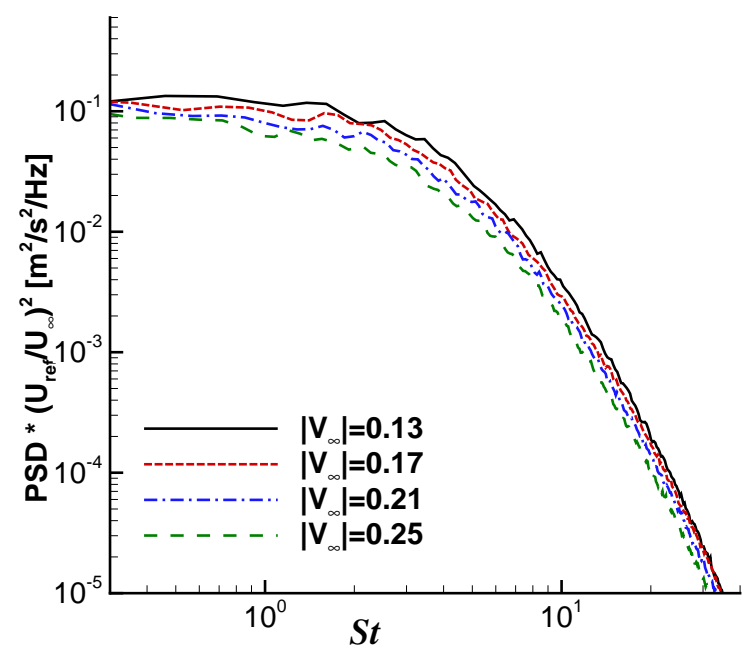

(d) $S / S_{\max }=0.81$

Figure 9. Power spectral density of the $v$ velocities versus Strouhal number at 4 locations defined by $S / S_{\max }$ along the trajectory of the slat cove shear layer shown in Fig. 4. The reference velocity $U_{\text {ref }}=0.17$. 


\section{III.A. Acoustics}

The far-field noise was calculated using the Ffowcs Williams-Hawkings (FW-H) equation ${ }^{30}$ frequency-domain solver described by Lockard. ${ }^{31}$ Calculations were also performed with a time-domain solver, and the results were consistent with those shown here. Unsteady flow data from the CFD calculations was recorded on the solid surfaces and a permeable surface. The surfaces are shown in Fig. 10, with the solid surface in black and the permeable surface in red. The data was extracted over the full span used in the CFD calculation. However, only half of the spanwise data was used in the FW-H calculations to avoid artificial interference effects caused by the periodic nature of the simulations. Hence, the noise predictions are for a spanwise segment that is $37 \%$ of the slat chord (approximately 1 in or $2.54 \mathrm{~cm}$ ). Predictions for longer spans could be calculated using corrections ${ }^{32}$ for the actual span of a body. The temporal record of 39,000 time steps was divided into 7 separate segments, where successive segments were overlapped by $50 \%$. Each segment was run through the FW-H solver independently, and the 7 individual results were then averaged.

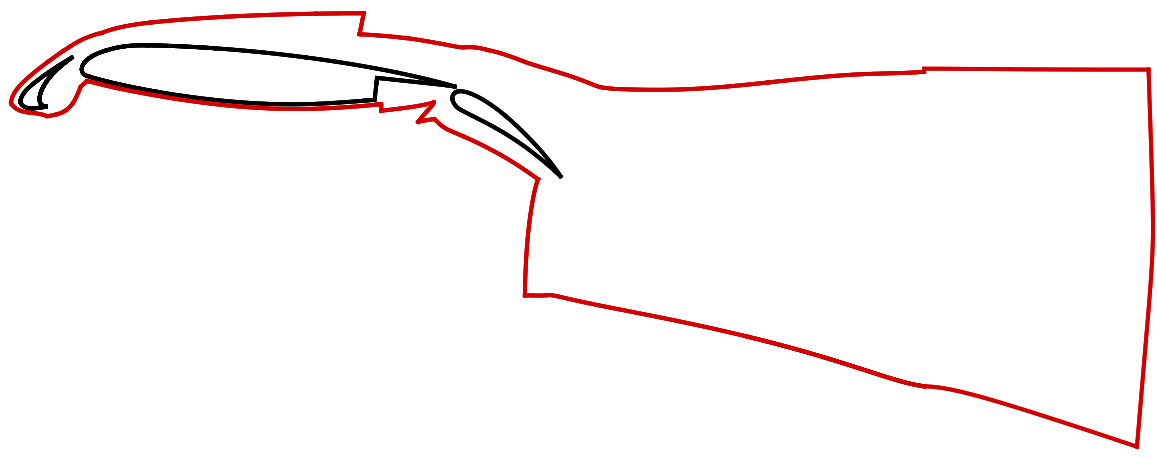

Figure 10. Surfaces used for FW-H calculations. Solid surface in black and the permeable surface in red.

The directivity scaled assuming $p^{\prime 2} \sim U_{\infty}^{5}$ is shown in Fig. 11. The distance from the slat trailing edge to the observers is 10 chords. The noise exhibits $1 / r$ decay at this distance as demonstrated in Ref. 22. The directivity was calculated for Strouhal numbers between 0.3 and 20 so that very low and very high frequency oscillations not adequately represented within the near-field data are excluded. The results from the solid (Fig. 11(a)) and permeable (Fig. 11(b)) surfaces are quite similar, although the collapse is slightly better for the permeable surface result in the upstream direction, presumably because that result includes some near-field convection effects because the quadrupoles within the surface are taken into account. However, the differences between the solid and permeable surface results are fairly negligible below the airfoil, which is the region most important for community noise. The highest Mach number result is slightly weaker than the assumed $p^{2} \sim U_{\infty}^{5}$ for angles around $300^{\circ}$. The data collapses better with $p^{2} \sim U_{\infty}^{4.5}$ around that angle. Furthermore, the ordering of the curves varies with position. Hence, experimental observations of the variation on the intensity with Mach number would be dependent on exactly where the measurements were taken. This may partly explain why dependencies from $U_{\infty}^{4}$ to $U_{\infty}^{5.5}$ have been reported in the literature.

The power spectral density of the pressure at four points between $270^{\circ}$ and $330^{\circ}$ (i.e., within the rear arc) are presented in Fig. 12. Results using the solid surfaces are shown in Fig. 12(a) - (d), and results for $290^{\circ}$ using the permeable surface are given in Fig. 12(e) and (f). The amplitude has been adjusted assuming $p^{\prime} \sim U_{\infty}^{5}$ and a reference velocity of $U_{\text {ref }}=0.17$. A prominent difference between the results corresponds to the presence of an additional tone near $S t=18$ in the $\left|V_{\infty}\right|=0.13$ case. No evidence of the narrowband peak is observed at the higher speeds. Nonetheless, using the Strouhal scaling, the collapse for the four cases is quite good. There is some difference at the peaks between $S t=2$ to 5, but the overall shape collapses reasonably well. The current data represents the average of 7 realizations with a bin width of $\Delta S t=0.074$ at $U_{\infty}=0.17$, corresponding to $48 \mathrm{~Hz}$. Unfortunately, the simulation data record is not long enough to allow sufficient averaging to smooth the curves as much as desired without using an excessively large bin width.

The solid (Fig. 12(b)) and porous (Fig. 12(e)) surface results are quite similar, except for $S t<1$. The wake from the flap separation appears to be influencing the porous surface result, especially for the lowest Mach number. The results without the amplitude scaling for the porous surface is shown in Fig. 12(f) to give some perspective on the actual differences in the results.

The spectra for the four points between $270^{\circ}$ and $330^{\circ}$ are plotted against the frequency instead of the Strouhal number in Figs. 13(a)-(d). The solid surfaces were used, and the PSD scaled according to $U_{\infty}^{5}$. Interestingly, purely 2-D simulations (combining 2-D near-field CFD with 2-D FW-H) predicted an approximately $U_{\infty}^{4}$ dependence of the acoustic radiation, ${ }^{15}$ which is consistent with the $U_{\infty}^{5}$ dependence of edge scattering of a 3-D source field. Thus, although three- 


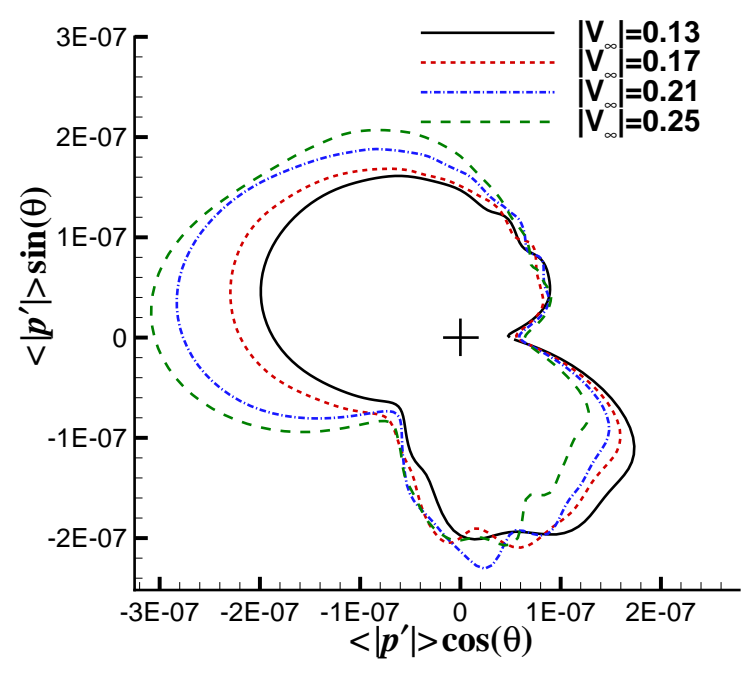

(a) Solid Surface

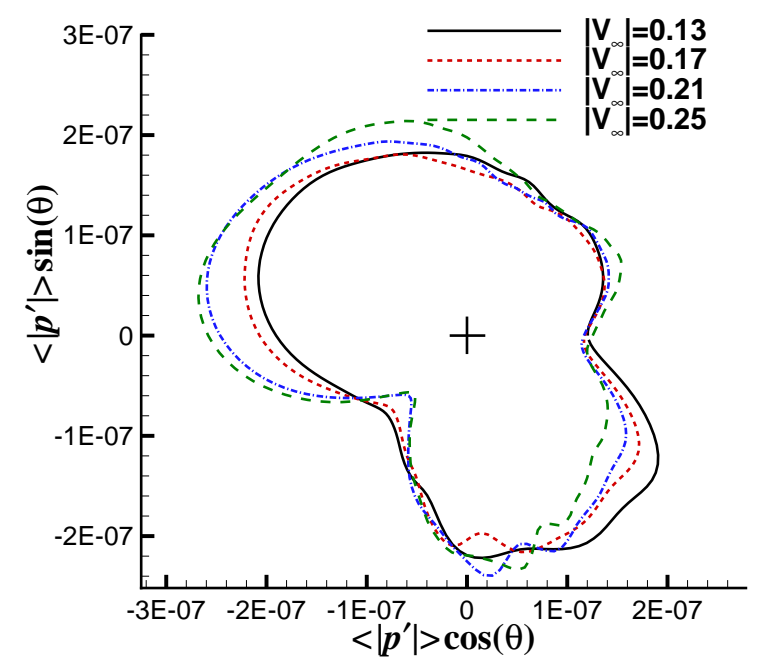

(b) Permeable Surface

Figure 11. FW-H predictions of the directivity. Observer is 10 chords from the slat trailing edge. Scaling performed assuming $p^{\prime 2} \sim U_{\infty}^{5}$ with $U_{\text {ref }}=0.17$.

dimensionality plays a critical role in capturing the correct behavior of near-field fluctuations, the mechanisms underlying the conversion of hydrodynamic fluctuations to acoustic perturbations are likely to be similar in both 2-D and 3-D cases.

Comparing Figs. 12 and 13, the Strouhal scaling did a better overall job of collapsing the data, especially the $\left|V_{\infty}\right|=0.13$ case. However, there are some features in the spectra that are better aligned using the frequency, such as the plateau between 5 to $7 \mathrm{kHz}$ visible at $310^{\circ}$ and $330^{\circ}$. The correct amplitude scaling in this range also appears to be different. Clearly, the spectra is comprised of a combination of disparate physical phenomena which scale differently with the flow speed. Nonetheless, the peak of the spectrum appears to vary with $U_{\infty}^{5}$. 


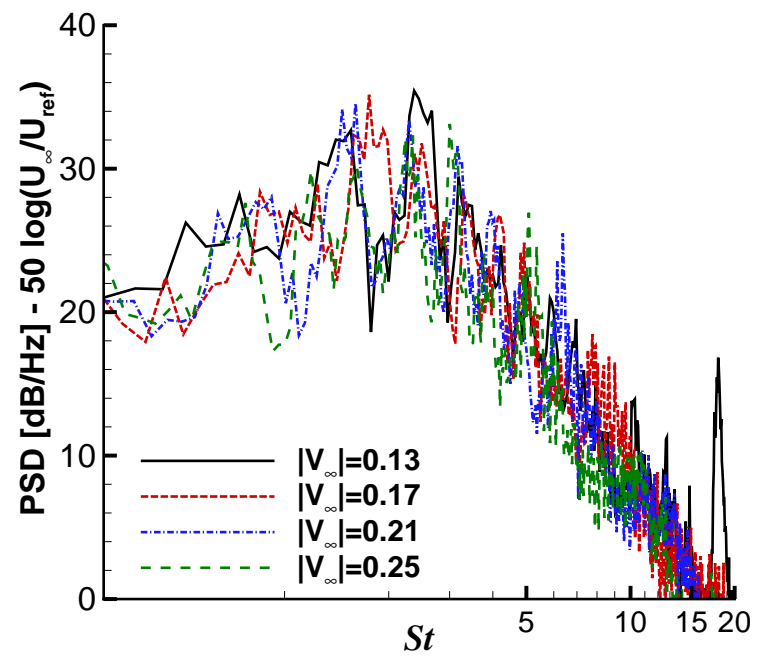

(a) $270^{\circ}$

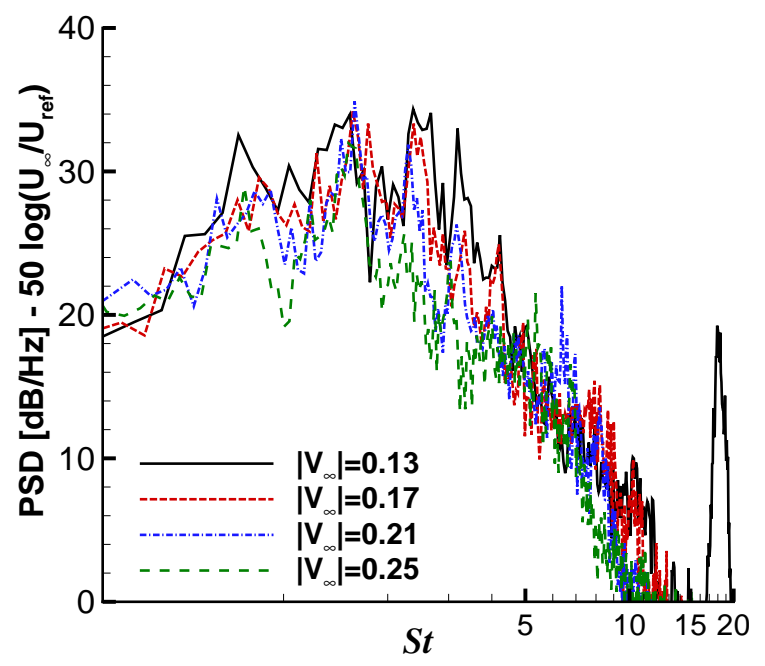

(c) $310^{\circ}$

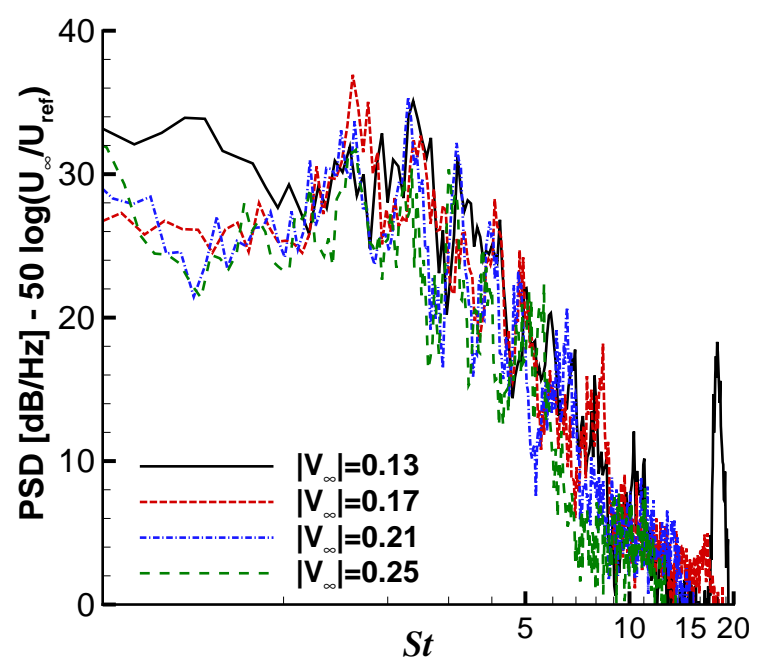

(e) $290^{\circ}$ (Permeable)

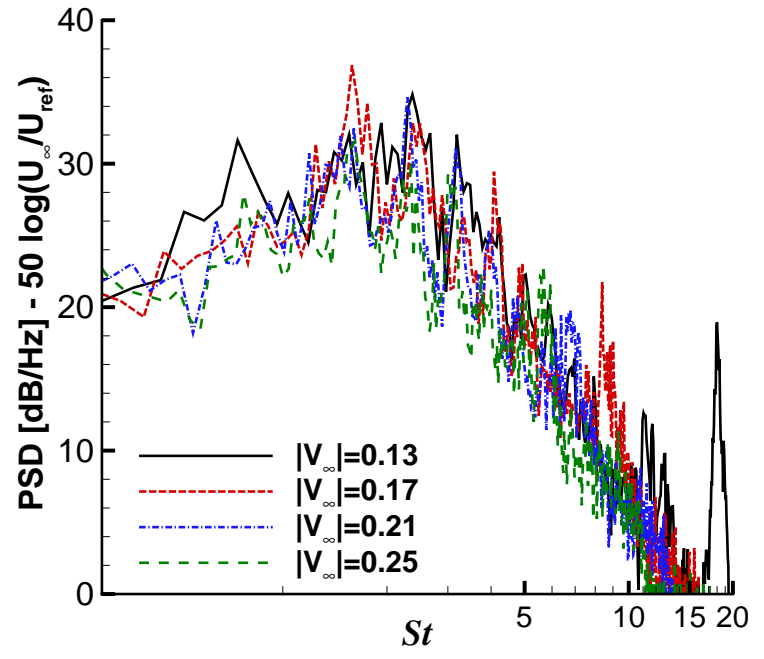

(b) $290^{\circ}$

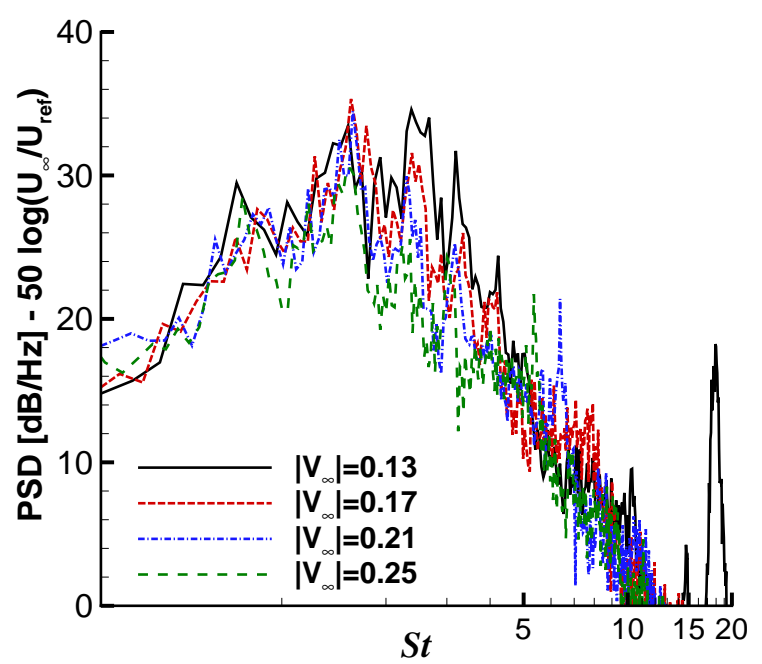

(d) $330^{\circ}$

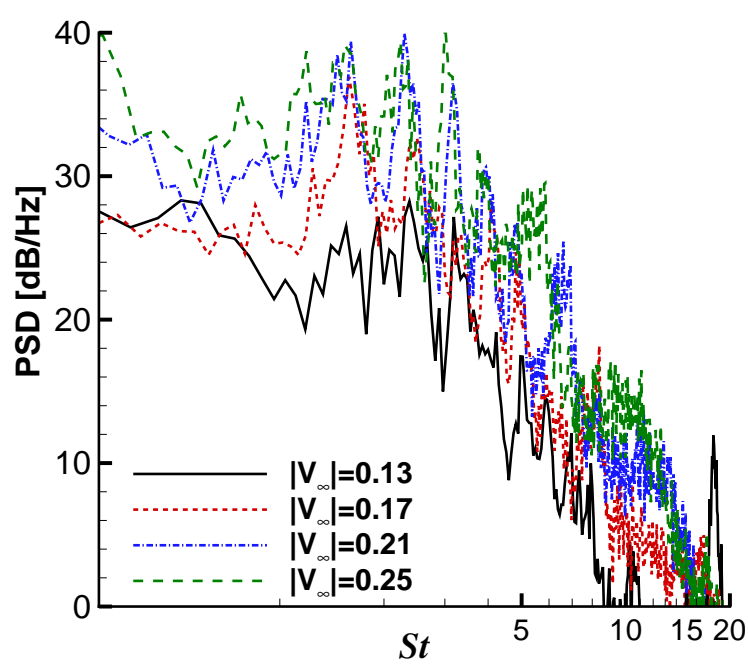

(f) $290^{\circ}$ (Permeable, Unscaled)

Figure 12. FW-H predictions of the power spectral density versus Strouhal number at several angles for observers located 10 chords from the slat trailing edge. Spectra have been scaled assuming $p^{\prime 2} \sim U_{\infty}^{5}$ with $U_{\text {ref }}=0.17$. 


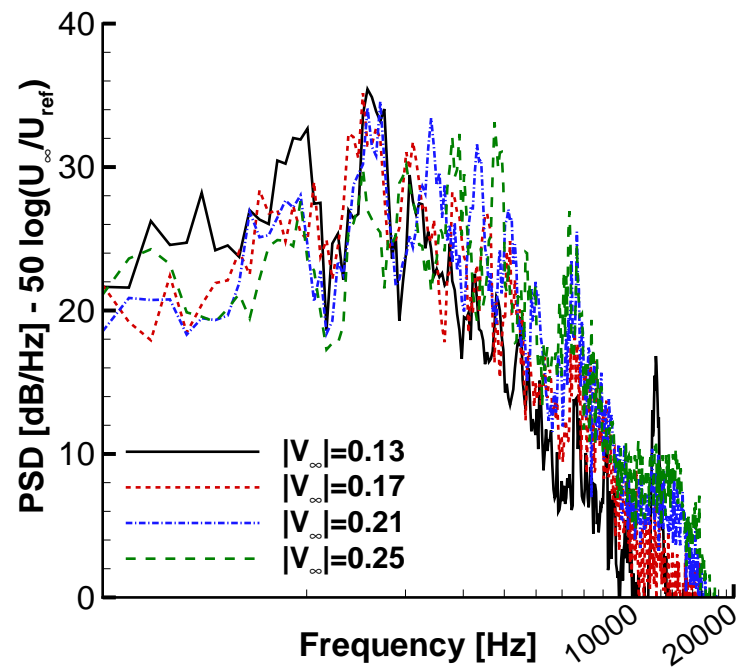

(a) $270^{\circ}$

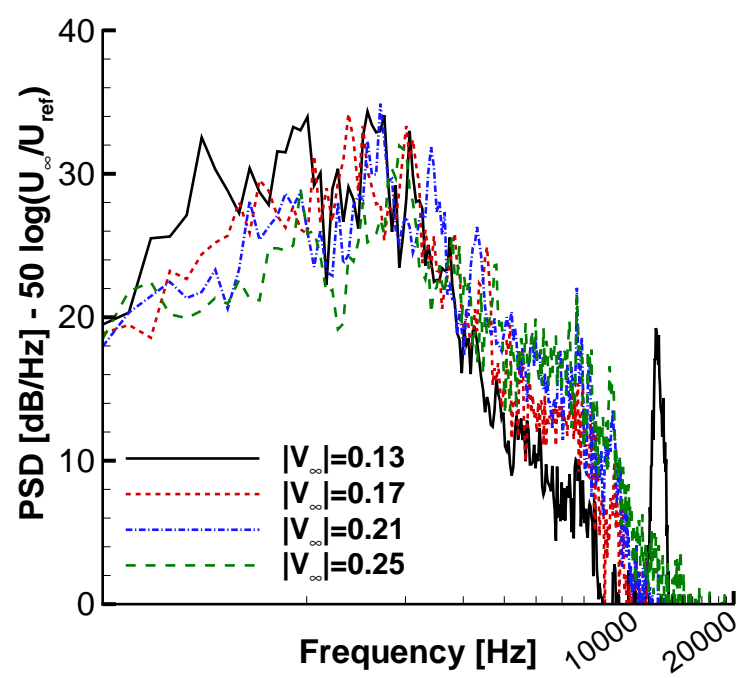

(c) $310^{\circ}$

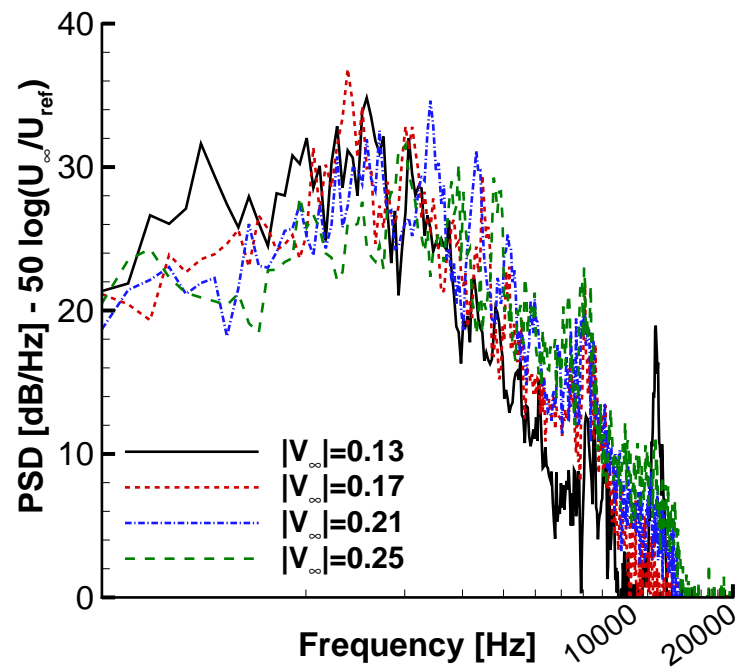

(b) $290^{\circ}$

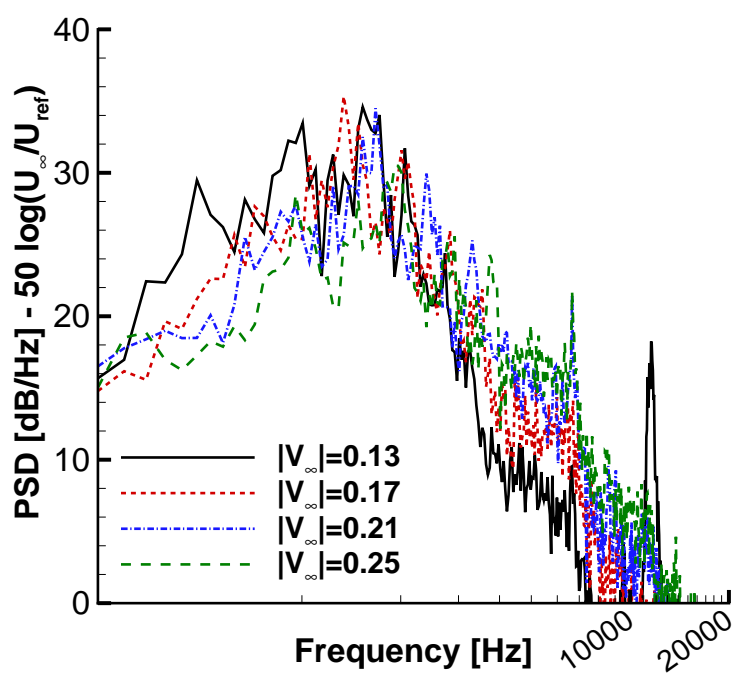

(d) $330^{\circ}$

Figure 13. FW-H predictions of the power spectral density versus frequency at several angles for observers located 10 chords from the slat trailing edge. Spectra have been scaled assuming $p^{\prime 2} \sim U_{\infty}^{5}$ with $U_{\text {ref }}=0.17$. 


\section{Results: Variation with Reynolds Number}

A study of the dependence of the results on the Reynolds number has also been performed at the baseline Mach number of 0.17. The range of Reynolds numbers was chosen to match those used in the study of the effect of sweep in Ref. 24 because distinct peaks in the surface pressure and acoustic spectra did not appear in a case with $\operatorname{Re}_{c}=2.418$ million. The mean distributions of the pressure coefficient are shown in Fig. 14 from three calculations with the Reynolds number varying from 1.209 to 2.418 million. The $C p$ results are relatively insensitive to this small change in $\operatorname{Re}_{c}$. Similarly, the rms of $C p^{\prime}$ on the slat in Fig. 15 shows only minor variation between the four cases, with the peak pressure fluctuations over the slat surface increasing slightly with the Reynolds number. The high $\operatorname{Re}_{c}$ data from Ref. 33 shows a substantially reduced extent of flap separation between $\operatorname{Re}_{c}$ of 6 and 9 million which will influence the loading on the slat. Although none of the $\operatorname{Re}_{c}$ in the current study are in the range of those examined in Ref. 33, the flap separation does appear to be reduced in the higher Reynolds number cases.

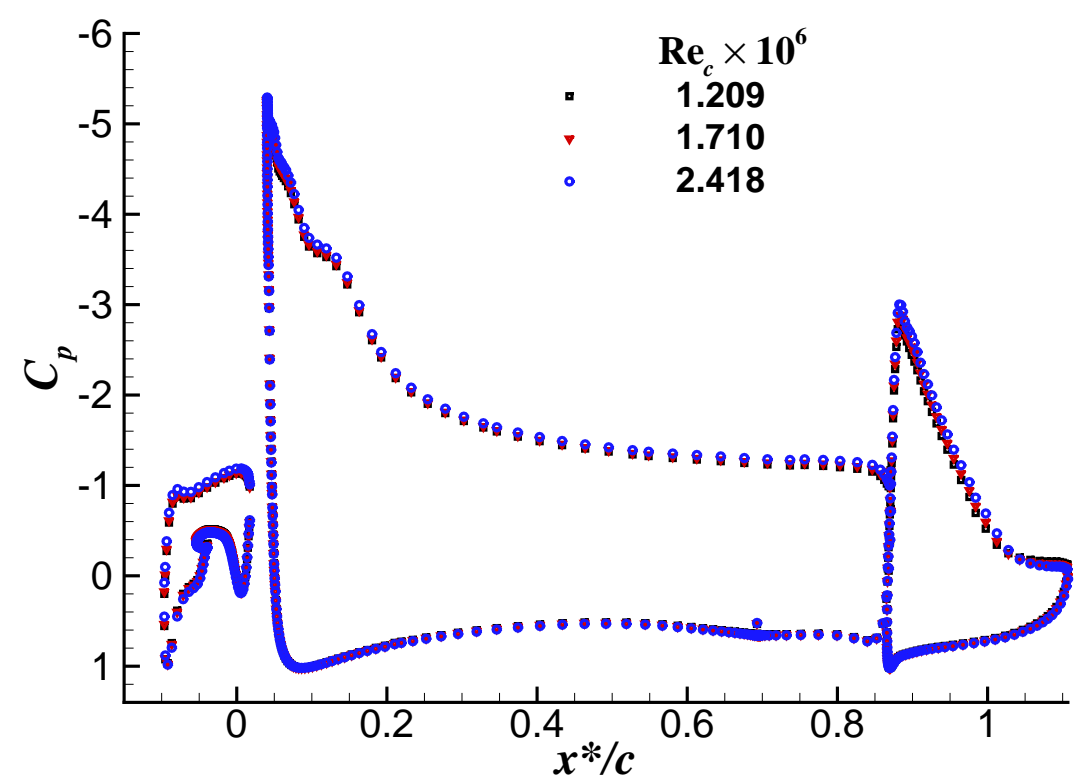

Figure 14. Coefficient of pressure on the airfoil.

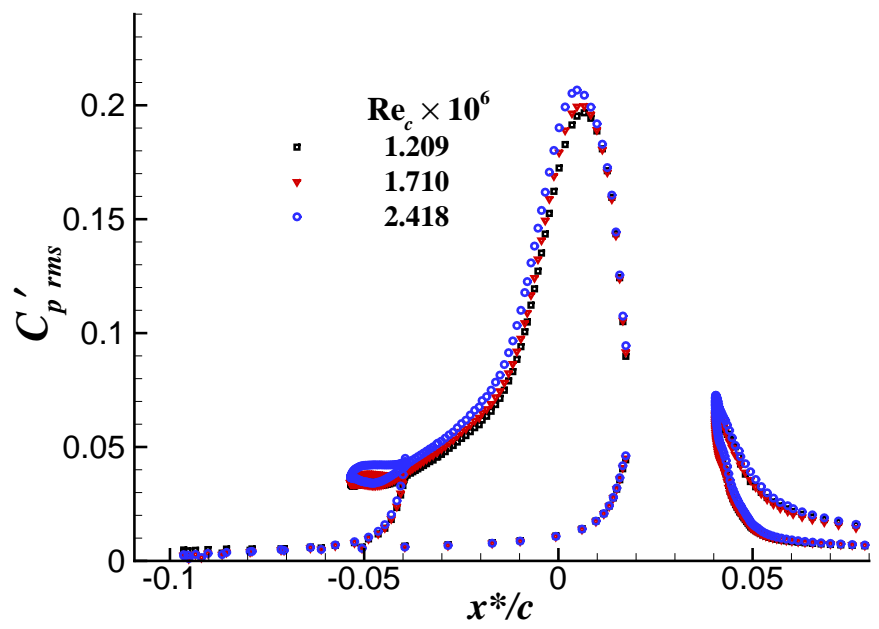

Figure 15. Fluctuating $C p^{\prime}$ on the slat.

The spectra at the 6 surface points identified in Fig. 4 are presented in Fig. 16. Except for point 2, all of the results are nearly identical. Point 2 is inside the recirculation zone, and high intermittency in that region is the likely cause of the discrepancy. Similarly, the spectra of $u$ and $v$ show very little difference between the three cases. Even the details of the peaks in Fig. 16(f) are nearly identical. 


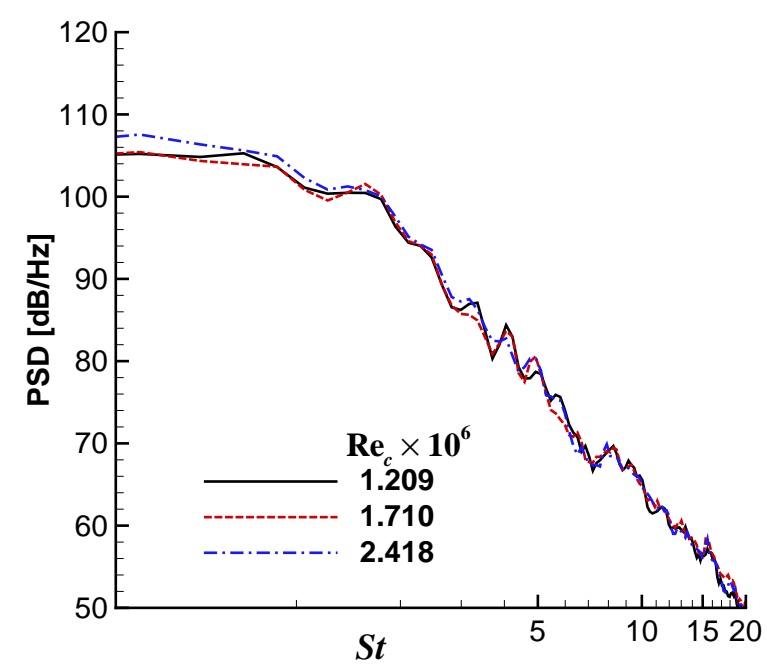

(a) Point 1

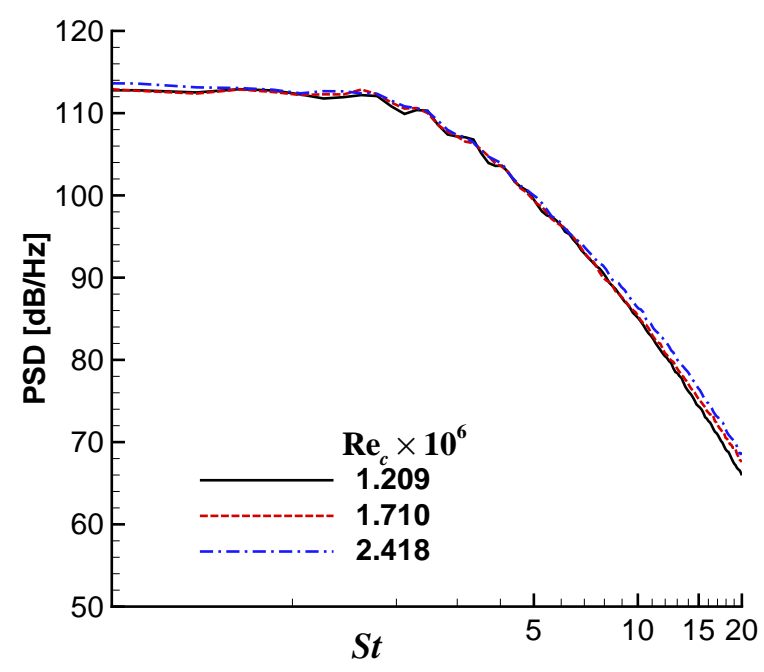

(c) Point 3

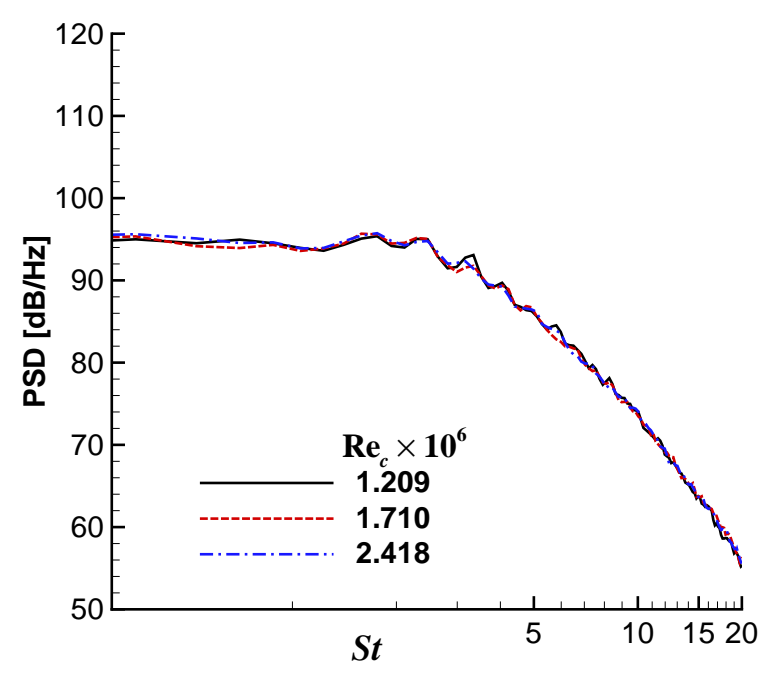

(e) Point 5

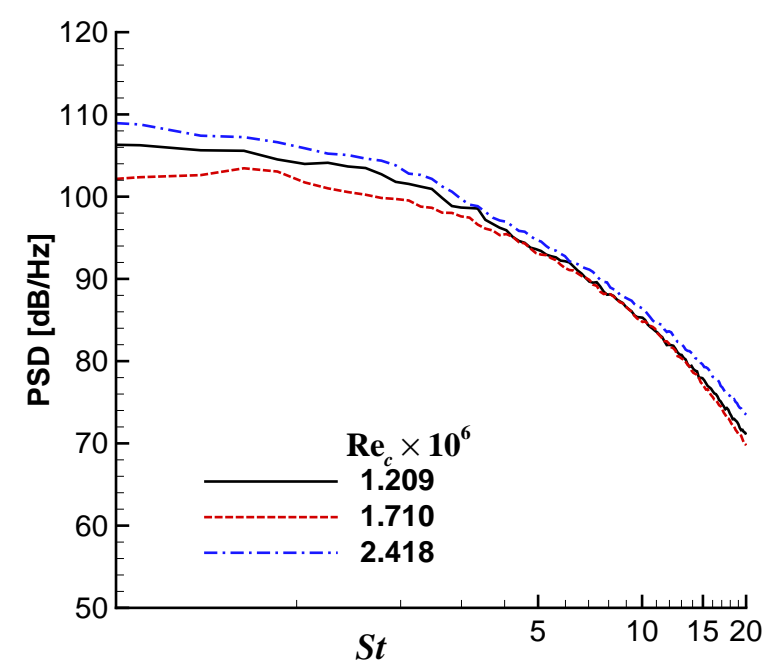

(b) Point 2

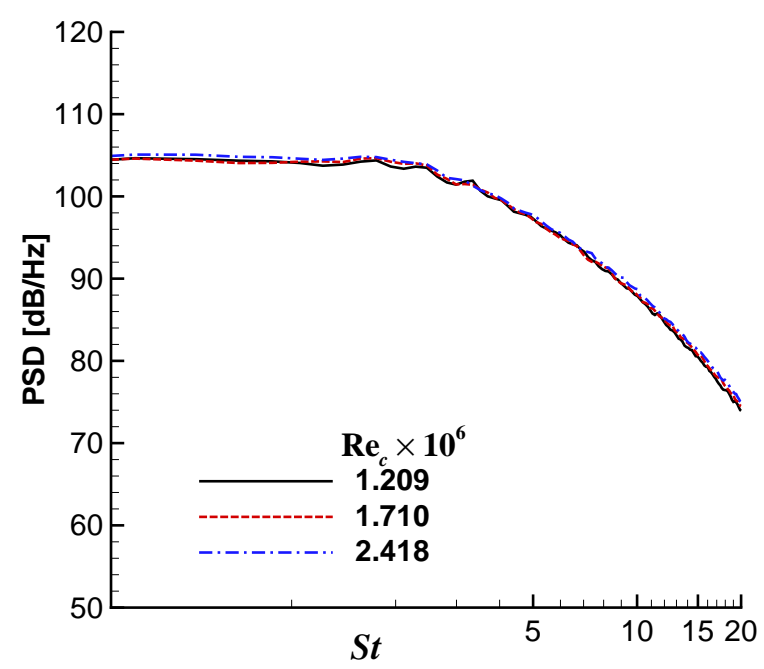

(d) Point 4

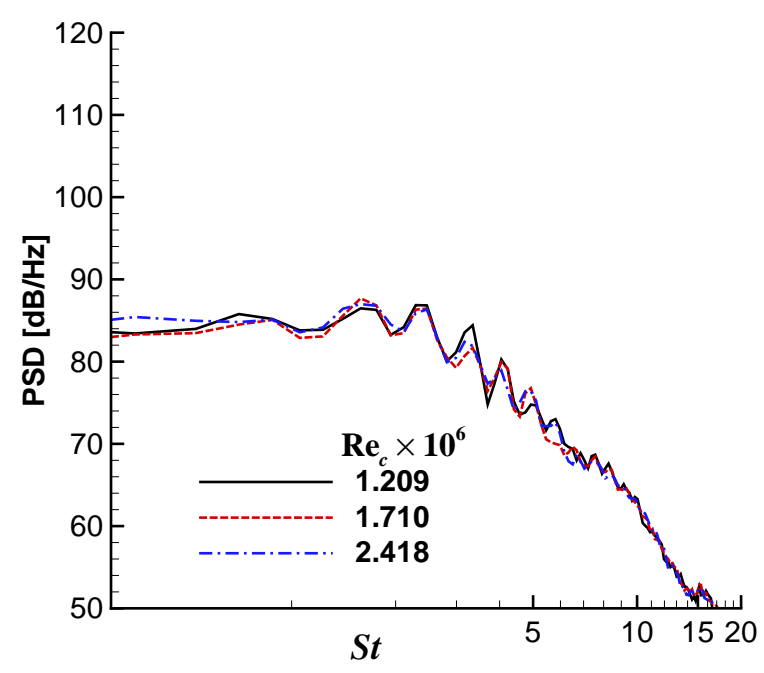

(f) Point 6

Figure 16. Power spectral density versus Strouhal number at the 6 points in Fig. 4. 


\section{IV.A. Acoustics}

The directivity computed using the solid surface data in the FW-H solver is presented in Fig. 17(a). Even on this linear scale, the difference between the four cases is very small. Furthermore, the details of the spectra at $290^{\circ}$ are similar between the cases as shown in Fig. 17(b). Some differences are evident below $S t=1$, but it is unclear if this is because of insufficient sample length or because of the oscillations in the flap separated region, which tend to be at very low frequency, are affected by the $\mathrm{Re}_{c}$. Nonetheless, the Reynolds number variation study turned out to be a good demonstration of the repeatability of the simulations, although doing little to reveal anything meaningful about the effect of $\operatorname{Re}_{c}$. However, this range of Reynolds numbers did produce notable changes in acoustic spectra in the study of the effect of sweep in Ref. 24. That study found that the distinct peaks in the spectra did not appear in a case with $\operatorname{Re}_{c}=2.418$ million. Clearly, the $\operatorname{Re}_{c}$ alone was not responsible for this change, and the sweep was also playing an important role.

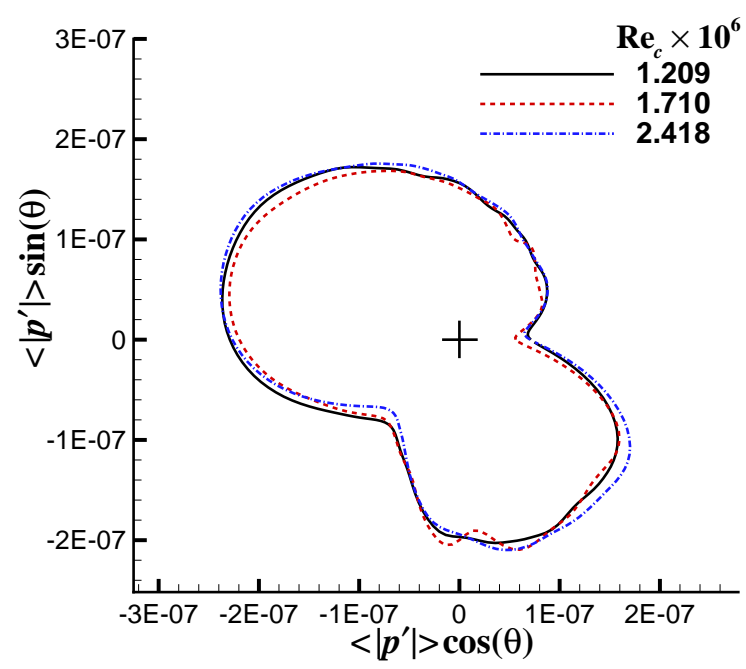

(a) Directivity

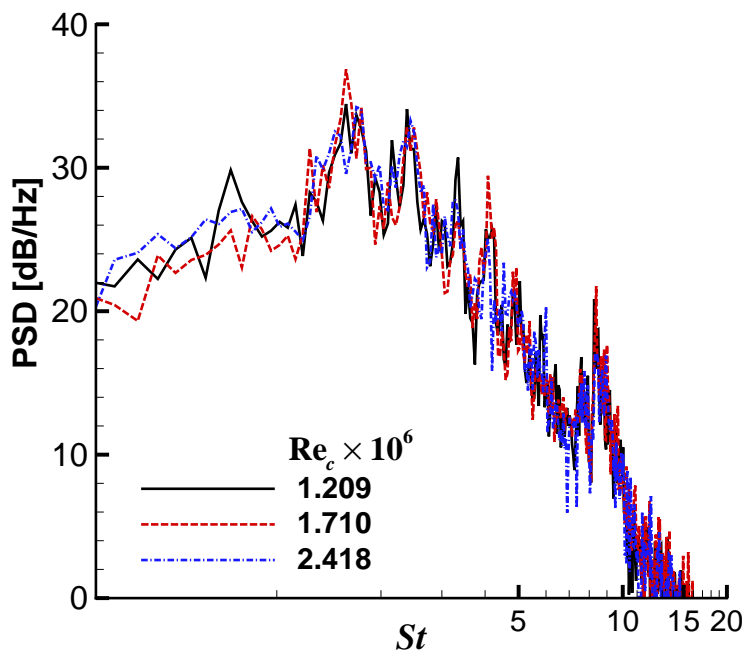

(b) Spectra at $290^{\circ}$

Figure 17. FW-H predictions of the directivity and PSD. Observer is 10 chords from the slat trailing edge.

\section{Results: Variation with Turbulence Model}

Simulations have been completed at $\left|\mathbf{V}_{\infty}\right|=0.17$ and 0.25 with $\operatorname{Re}_{c}=1.71$ million using the MDDES $^{29}$ methodology to compare with the baseline SST results with the Quasi-Laminar cove (SST QL). As mentioned in the introduction, the MDDES methodology automatically switches between RANS and LES regions based on the proximity to solid surfaces, local flow field, and grid spacing. The comparison of the surface pressure coefficient results in Fig. 18 reveals that the turbulence model is having a greater impact than the small Re variations studied earlier. However, the differences seem to be primarily related to how the models predict the separation on the flap. For both Mach numbers, the MDDES results show very little separation on the flap, whereas the SST QL cases both indicate separation occurs around the middle of the flap chord. Hence, the loading distribution is higher for MDDES. The 5.5 angle of attack used in the free-field simulations was chosen to mimic the pressure distribution obtained by Jenkins ${ }^{17}$ in the BART tunnel with an angle of attack of $4^{\circ}$. At $4^{\circ}$, the experiment did exhibit flap separation. Obviously, the $C p$ distribution from the MDDES calculation would not match with the BART measurements without at least an adjustment to the angle of attack.

Although the loading on the slat is higher with MDDES, the fluctuating levels are actually lower. Figure 19 presents the rms of $C p^{\prime}$ on the slat. For both Mach numbers, the fluctuations from the MDDES calculations are lower than their SST QL counterparts, most noticeably near the peak around $x=0.005$. The suppressed fluctuations may partly be an artifact of the different pressure distribution and associated flowfield, but the MDDES calculation also has higher values of eddy viscosity in the slat cove region compared to SST QL where the production term is completely turned off inside the cove. Interestingly, the MDDES calculation exhibited higher fluctuation levels on the flap than SST QL.

The MDDES 2-D velocity magnitude and 3-D TKE in the slat cove for $\left|\mathbf{V}_{\infty}\right|=0.17$ are presented in Fig. 20. The normalized velocity results for $\left|\mathbf{V}_{\infty}\right|=0.25$ are almost indistinguishable from those shown in Fig. 20(a), but the 3-D TKE levels at the higher Mach number are increased in a similar fashion to that observed with SST QL. A careful comparison of Figs. 20(a) and 4(b) reveals that the reattachment point in the MDDES calculation is slightly upstream compared with the SST QL case. Hence, the shear layer trajectory is slightly different. Furthermore, the comparison of 


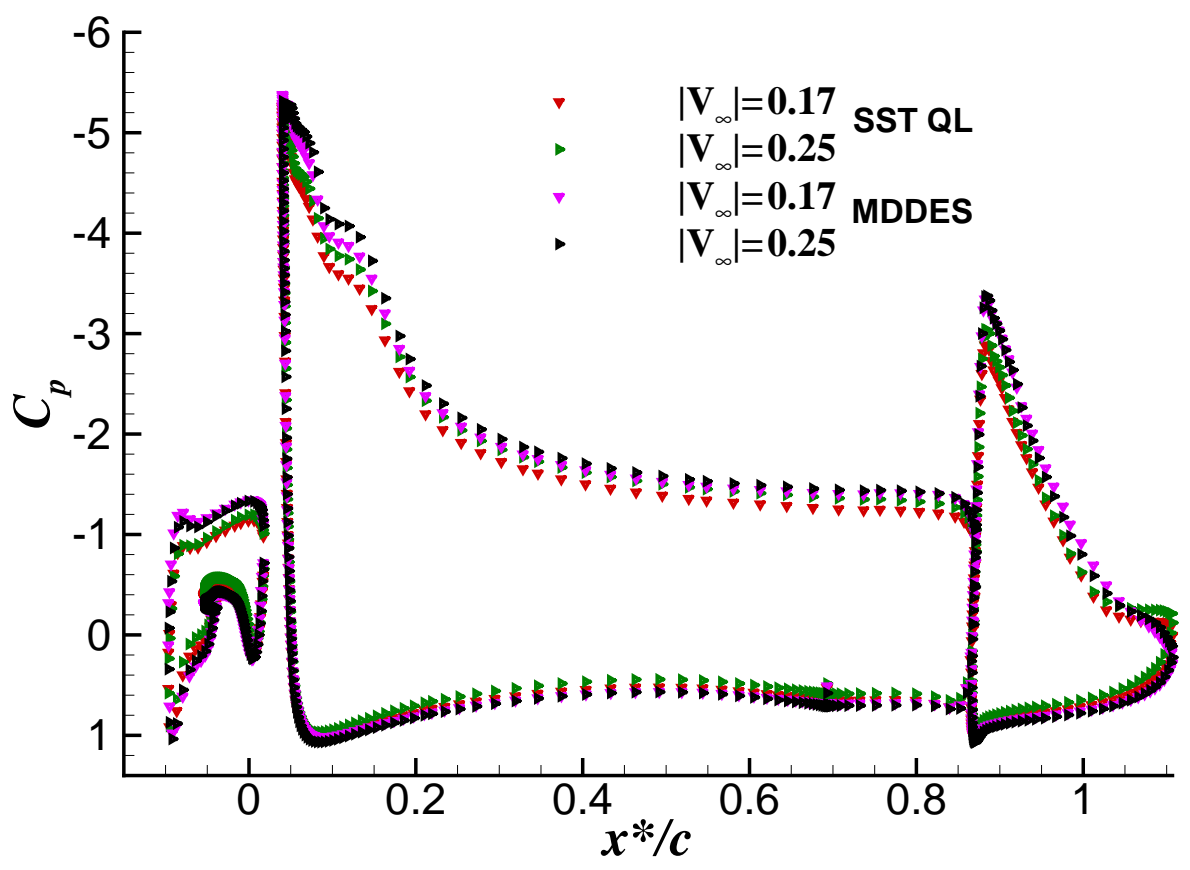

Figure 18. Coefficient of pressure on the airfoil.

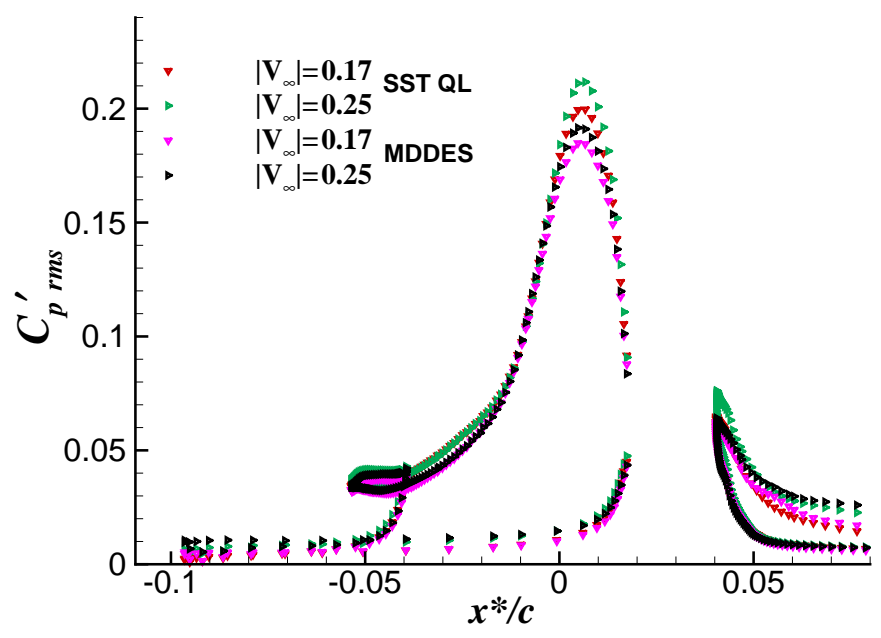

Figure 19. Fluctuating $C p^{\prime}$ on the slat.

Figs. 20(b) and 5(b) indicates that the fluctuation levels are slightly higher with MDDES in the portion of the cove shear layer near the cusp, but SST QL has higher levels near the reattachment point. Nonetheless, the overall patterns are quite similar.

The spectra on the six surface points indicated in Fig. 20(a) are presented in Fig. 21. At $\left|\mathbf{V}_{\infty}\right|=0.17$, the MDDES and SST QL results are quite similar, but at $\left|\mathbf{V}_{\infty}\right|=0.25$ the SST QL levels are slightly higher in the low frequencies. The same trends are observed in the spectra of the velocities along the shear layer shown in Figs. 22 and 23. The peak in Fig. 22(a) of the MDDES $u$ velocity spectra at $S / S_{\max }=0.20$ is at a lower frequency and at higher levels than the SST QL result, indicating a thicker shear layer. Most likely, the combination of the altered velocity distribution and the boundary layer being slightly different coming off the bottom of the slat into the cusp contributes to the altered shear layer state and initial growth of the fluctuations. However, by $S / S_{\max }=0.60$, the history of the initial growth appears to have been lost, and the spectra look remarkably similar. Even the small tones most evident at $S / S_{\max }=0.81$ appear at the same frequencies. Considering that the trajectory of the shear layer is shifted slightly upstream in the MDDES calculation, more differences were anticipated. 


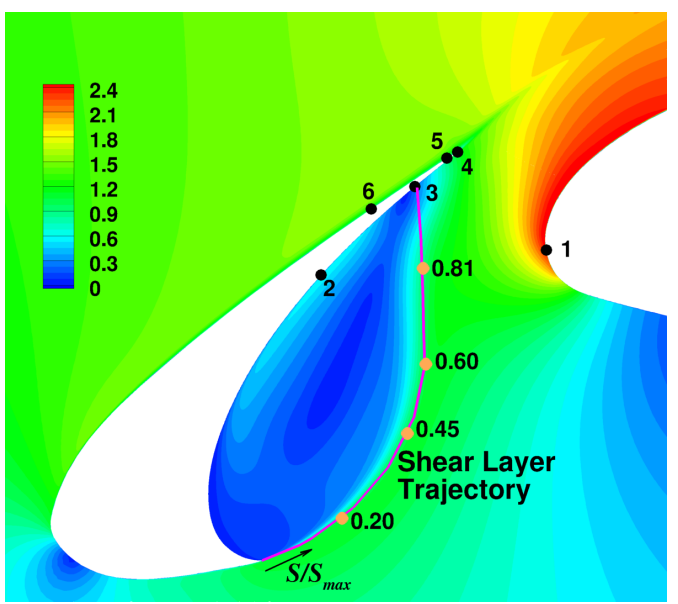

(a) $\left|\mathbf{V}_{2 D}^{*}\right| /\left|\mathbf{V}_{\mathbf{o}}\right|$

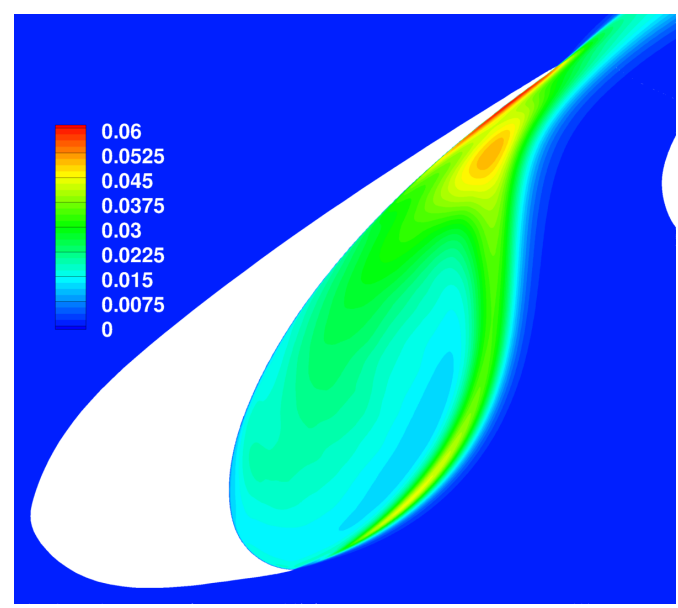

(b) 3-D TKE

Figure 20. MDDES results for $\left|\mathbf{V}_{\infty}\right|=0.17$

\section{V.A. Acoustics}

A comparison of the directivities at $\left|\mathbf{V}_{\infty}\right|=0.17$ and 0.25 between the MDDES and SST QL results is presented in Fig. 24. The two results at $\left|\mathbf{V}_{\infty}\right|=0.17$ are nearly identical both in terms of magnitude and shape. However, at $\left|\mathbf{V}_{\infty}\right|=0.25$, the SST QL result has a larger magnitude in the second and fourth quadrants, but the patterns are still similar. The spectra at $310^{\circ}$ reveals that the primary difference between the MDDES and SST QL results is in the lower frequencies where the MDDES spectra exhibits tones that reach the levels of the SST QL result but are otherwise lower. From the peak of the spectra to higher frequencies, the two results are quite similar as are the two at $\left|\mathbf{V}_{\infty}\right|=0.17$ over the entire frequency range. Despite the altered mean flows, the acoustic fields are quite similar. The main difference is the lower fluctuation levels at lower frequencies at $\left|\mathbf{V}_{\infty}\right|=0.25$ with MDDES, which makes the $U_{\infty}^{5}$ scaling appear too strong in the fourth quadrant.

\section{Conclusions}

The present simulations help clarify the dependence of slat noise on the Mach and Reynolds numbers. Such an understanding is needed for improved modeling, and it will lay the foundation for future examinations of important parameters such as the angle of attack, slat gap, and slat deflection.

Four simulations were performed with the Mach number varying from 0.13 to 0.25 . Near-field pressure fluctuations were found to scale approximately with $U_{\infty}^{4}$ whereas the far-field acoustics scaled roughly with $U_{\infty}^{5}$. The collapse in the acoustic field for the four Mach numbers was the worst in the second and fourth quadrants, and the directivity pattern exhibited some changes below the airfoil. The region of the fourth quadrant is of particular significance for community noise. Nonetheless, the general character of slat noise appears relatively consistent within the range of Mach numbers studied, at least to within the fidelity of current airframe noise prediction methods.

The study of the effect of Reynolds number did not reveal any significant differences when $\operatorname{Re}_{c}$ was varied from 1.4 to 2.4 million at the baseline Mach number of 0.17. However, the three cases did demonstrate that the overall computational results are repeatable. An earlier study on cross flow indicated that the small tones observed in the acoustic spectra disappeared at a Reynolds number of 2.4 million and Mach number of 0.13 . The tones were still present in the current simulation results, indicating that the cross flow played a role.

All of the previous computations have been performed using a Quasi Laminar cove region and the SST turbulence model. Simulations using the MDDES hybrid RANS/LES turbulence model were conducted at the baseline Reynolds number and Mach numbers of 0.17 and 0.25 . The MDDES results showed very little flap separation compared with SST QL. Thus, the overall lift distribution and mean flow was slightly different. Although this resulted in some identifiable differences in the near-field fluctuations, the acoustics at $\left|\mathbf{V}_{\infty}\right|=0.17$ was remarkably similar for the two turbulence models. However, lower near- and far-field fluctuation levels were noted in the lower frequencies for MDDES. Nonetheless, the general trends observed with Mach number were similar for both turbulence models.

The results appear to indicate that the slat noise source is fairly robust, and primarily only amplitude changes result from Mach number variations within the range of those that might be used in landing operations. Future studies will examine the influence of more realistic Reynolds numbers and the angle of attack. 


\section{Acknowledgments}

This work was supported by the NASA Fundamental Aeronautics Program's Subsonic Fixed-Wing Project. The authors gratefully acknowledge the assistance of Mr. M. R. Wiese from Analytical Services and Materials, Inc., who generated the computational grid used during the present study.

\section{References}

${ }^{1}$ Hayes, J. A., Horne, W. C., Soderman, P. T., and Bent, P. H., “Airframe Noise Characteristics of a 4.7\% Scale DC-10 Model," AIAA Paper 1997-1594, 1997.

${ }^{2}$ Storms, B. L., Ross, J. C., Horne, W., Hayes, J., Dougherty, R. P., Underbrink, J. R., Scharpf, D. F., and Moriarty, P. J., "An Aeroacoustic Study of an Unswept Wing with a Three-Dimensional High Lift System," NASA TM 112222, February 1998.

${ }^{3}$ Dobrzynski, W., Nagakura, K., Gehlhar, B., and Buschbaum, A., "Airframe Noise Studies on Wings with Deployed High-Lift Devices," AIAA Paper 1998-2337, 1998.

${ }^{4}$ Storms, B. L., Hayes, J. A., Moriarty, P. J., and Ross, J. C., "Aeroacoustic Measurements of Slat Noise on a Three-Dimensional High-Lift System," AIAA Paper 1999-1957, 1999.

${ }^{5}$ Choudhari, M. M., Lockard, D. P., Macaraeg, M. G., Singer, B. A., Streett, C. L., Neubert, G. R., Stoker, R. W., Underbrink, J. R., Berkman, M. E., Khorrami, M. R., and Sadowski, S. S., "Aeroacoustic Experiments in the Langley Low-Turbulence Pressure Tunnel," NASA TM-211432, February 2002.

${ }^{6}$ Mendoza, F. and Brooks, T., "Aeroacoustic Measurements of a Wing/Slat Model," AIAA Paper 2002-2604, 2002.

${ }^{7}$ Chow, L. C., Mau, K., and Remy, H., “Landing Gears and High Lift Devices Airframe Noise Research,” AIAA Paper 2002-2408, 2002.

${ }^{8}$ Dobrzynski, W. and Pott-Pollenske, M., "Slat Noise Source Studies for Farfield Noise Prediction,” AIAA Paper 2001-02158, 2001.

${ }^{9}$ Guo, Y., Yamamoto, K., and Stoker, R., "Component Based Empirical Model for High-Lift System Noise Prediction," Journal of Aircraft, Vol. 40, No. 5, 2003, pp. 914-922.

${ }^{10}$ Guo, Y. and Joshi, M., "Noise Characteristics of Aircraft High-Lift Systems," AIAA Journal, Vol. 41, No. 7, 2003, pp. $1247-1256$.

${ }^{11}$ Khorrami, M. D., Berkman, M. E., and Choudhari, M., "Unsteady flow compuations of a slat with a blunt trailing edge," AIAA Journal, Vol. 38 , No. 11, 2000, pp. 2050-2058.

${ }^{12}$ Singer, B. A., Lockard, D. P., and Brentner, K. S., "Computational Aeroacoustic Analysis of Slat Trailing-Edge Flow," AIAA Journal, Vol. 38, No. 9, 2000, pp. 1558-1564.

${ }^{13}$ Khorrami, M. R., Singer, B. A., and Berkman, M. E., "Time-accurate Simulations and Acoustic Analysis of Slat Free Shear Layer," AIAA Journal, Vol. 40, No. 7, 2002, pp. 1284-1291.

${ }^{14}$ Khorrami, M. R., Singer, B. A., and Lockard, D. P., "Time-accurate Simulations and Acoustic Analysis of Slat Free Shear Layer: Part II," AIAA Paper 2002-2579, 2002.

${ }^{15}$ Choudhari, M., Khorrami, M. R., Lockard, D. P., Atkins, H. L., and Lilley, G. M., "Slat Cove Noise Modeling: A Posteriori Analysis of Unsteady RANS Simulations," AIAA Paper 2002-2468, 2002.

${ }^{16}$ Khorrami, M. R., Choudhari, M. M., and Jenkins, L. M., "Characterization of Unsteady Flow Structures Near Leading-Edge Slat: Part II. 2-D Computations," AIAA Paper 2004-2802, 2004.

${ }^{17}$ Jenkins, L. M., Khorrami, M. R., and Choudhari, M. M., "Characterization of Unsteady Flow Structures Near Leading-Edge Slat: Part I. PIV Measurements," AIAA Paper 2004-2801, 2004.

${ }^{18}$ Choudhari, M. M. and Khorrami, M. R., "Effect of Three-Dimensional Shear-Layer Structures on Slat Cove Unsteadiness," AIAA Journal, Vol. 45, No. 9, 2007, pp. 2174-2186.

${ }^{19}$ Rakhshani, B. and Filippone, A., "Three-Dimensional CFD Analysis of Slat Noise,” AIAA Paper 2008-0015, 2008.

${ }^{20}$ Imamura, T., Enomoto, S., Yokokawa, Y., and Yamamoto, K., "Three-Dimensional Unsteady Flow Computations Around a Conventional Slat of High-Lift Devices," AIAA Journal, Vol. 46, No. 5, 2008, pp. 1045-1053.

${ }^{21}$ Klausmeyer, S. M. and Lin, J., “Comparative Results from a CFD Challenge Over a 2D Three-Element High-Lift Airfoil,” NASA TM 112858, May 1997.

${ }^{22}$ Lockard, D. P. and Choudhari, M. M., "Noise Radiation from a Leading-Edge Slat," AIAA Paper 2009-3101, 2009.

${ }^{23}$ Imamura, T., Enomoto, S., Yokokawa, Y., and Yamamoto, K., "Simulation of the Broadband Noise from a Slat Using Zonal LES/RANS Hybrid Method," AIAA Paper 2007-0226, 2007.

${ }^{24}$ Lockard, D. P. and Choudhari, M. M., "The Effect of Cross Flow on Slat Noise,” AIAA Paper 2010-3835, 2010.

${ }^{25}$ Rumsey, C. L., Biedron, R. T., and Thomas, J. L., “CFL3D: Its History and Some Recent Applications,” NASA TM 112861, May 1997, presented at the Godonov's Method for Gas Dynamics Symposium, Ann Arbor, MI.

${ }^{26}$ Menter, F. R., "Two-equation Eddy-viscosity Turbulence Models for Engineering Applications,” AIAA Journal, Vol. 32, No. 8, 1994, pp. 15981605.

${ }^{27}$ Spalart, P. R., Deck, S., Shur, M. L., Squires, K. D., Strelets, M., and Travin, A. K., "A New Version of Detached-eddy Simulation, Resistant to Ambiguous Grid Densities," Theoretical Computional Fluid Dynamics, Vol. 20, 2006, pp. 181-195.

${ }^{28}$ Spalart, P. R. and Allmaras, S., “A One-Equation Turbulence Model for Aerodynamic Flows,” Recherche Aerospatiale, Vol. 1, No. 1, 1994, pp. 5-21.

${ }^{29}$ Vatsa, V. N. and Lockard, D. P., "Assessment of Hybrid RANS/LES Turbulence Models for Aeroacoustics Applications," AIAA Paper 20104001,2010

${ }^{30}$ Ffowcs Williams, J. E. and Hawkings, D. L., "Sound Generation by Turbulence and Surfaces in Arbitrary Motion," Philosophical Transactions of the Royal Society of London A, Vol. 342, 1969, pp. 264-321.

${ }^{31}$ Lockard, D. P., "A Comparison of Ffowcs Williams-Hawkings Solvers for Airframe Noise Applications," AIAA Paper 2002-2580, 2002.

${ }^{32}$ Seo, J. H., Chang, K. W., and Moon, Y. J., “Aerodynamic Noise Prediction for Long-Span Bodies,” AIAA Paper 2006-2573, May 2006.

${ }^{33}$ Chin, V. D., Peters, D. W., Spaid, F. W., and McGhee, R. J., "Flowfield Measurements about a Multi-element Airfoil at High Reynolds Numbers," AIAA Paper 1993-3137, 1993 


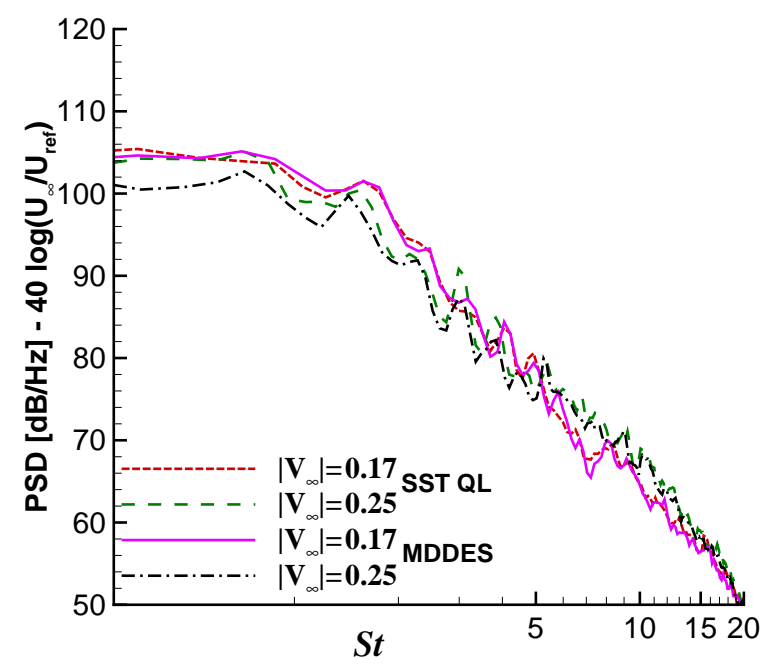

(a) Point 1

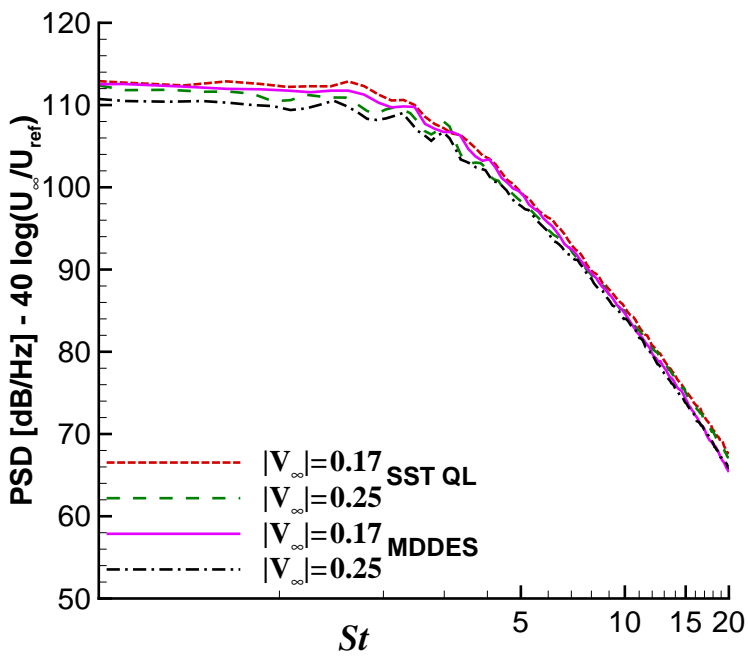

(c) Point 3

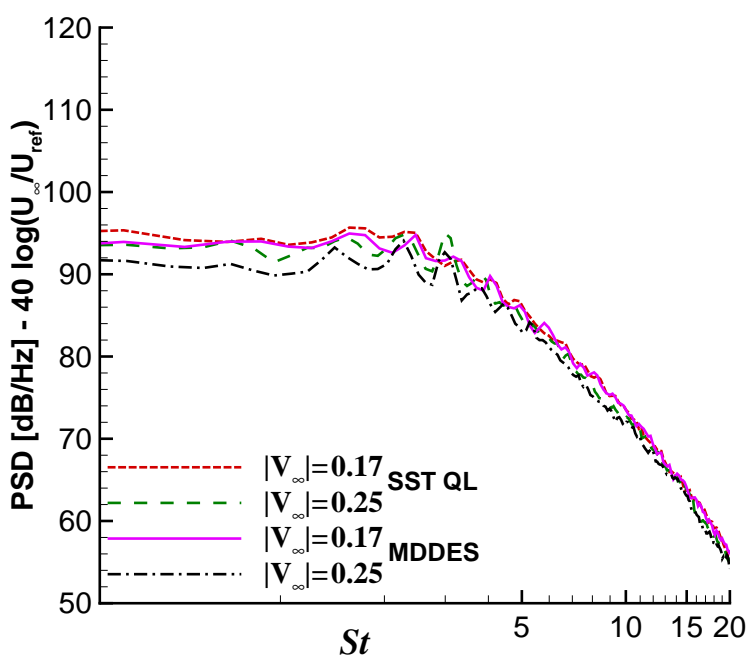

(e) Point 5

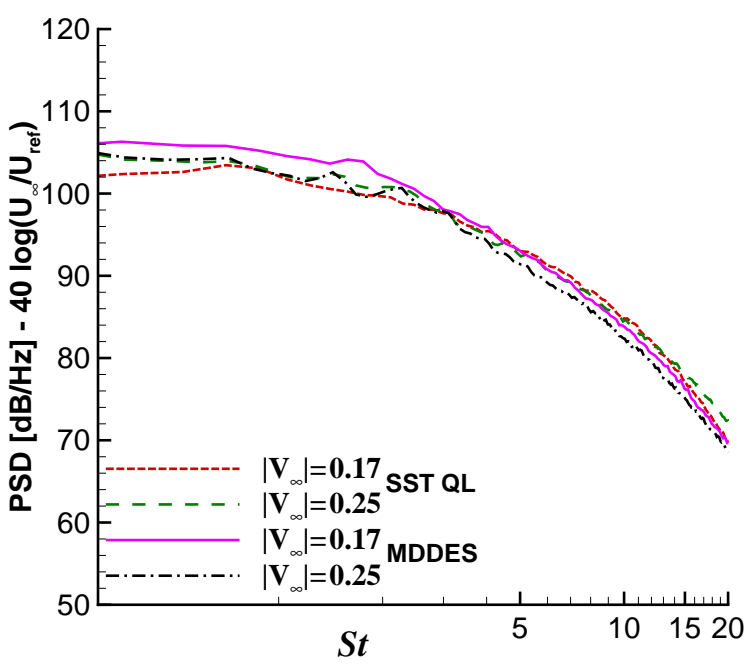

(b) Point 2

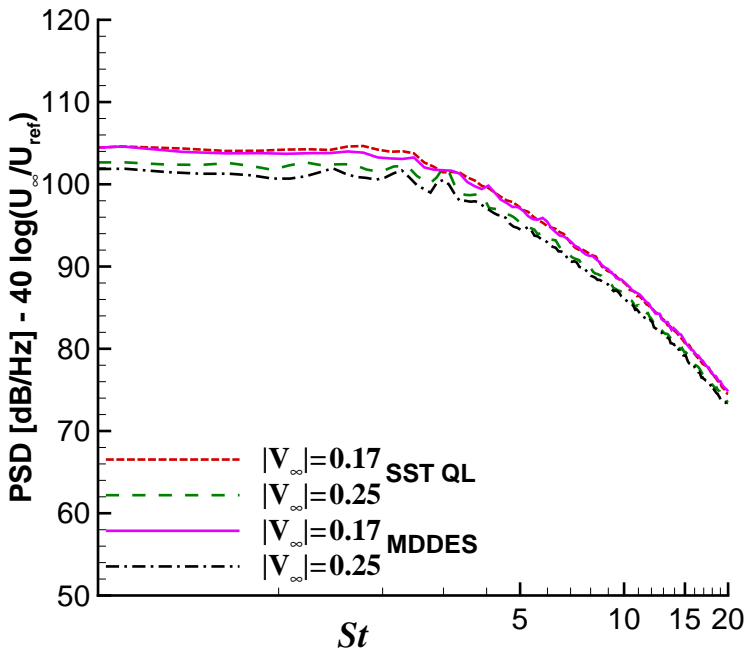

(d) Point 4

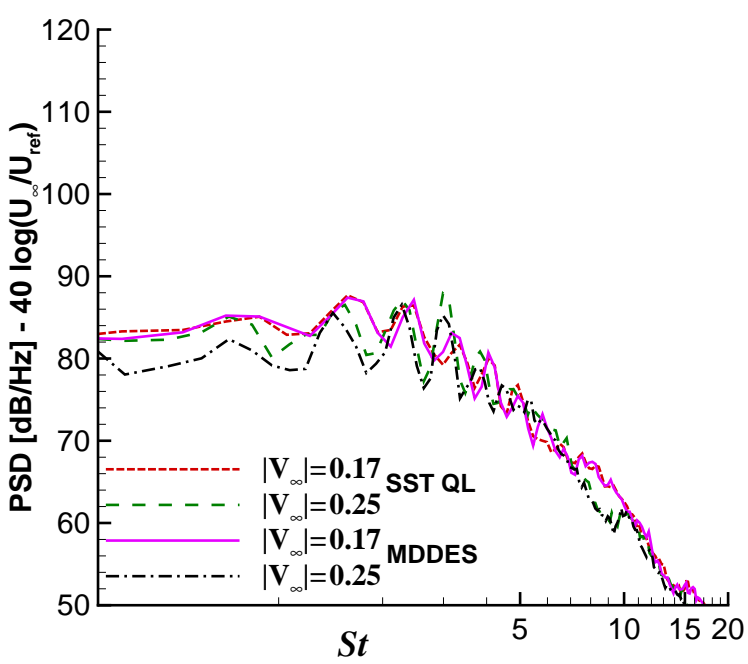

(f) Point 6

Figure 21. Power spectral density versus Strouhal number at the 6 points in Fig. 4. 


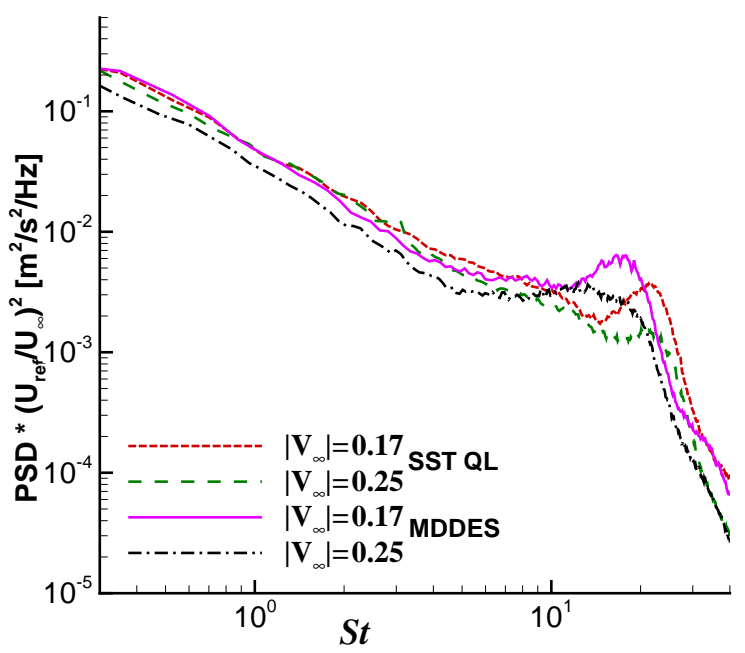

(a) $S / S_{\max }=0.20$

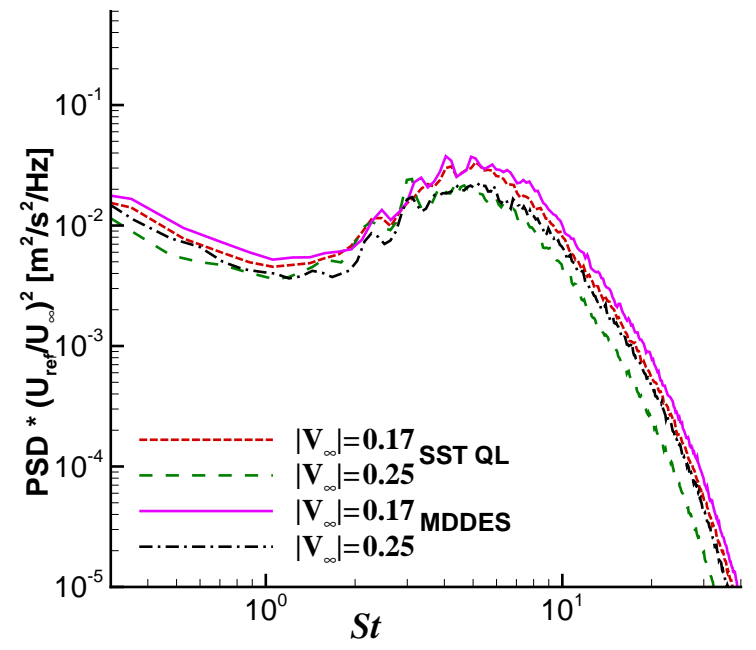

(c) $S / S_{\max }=0.60$

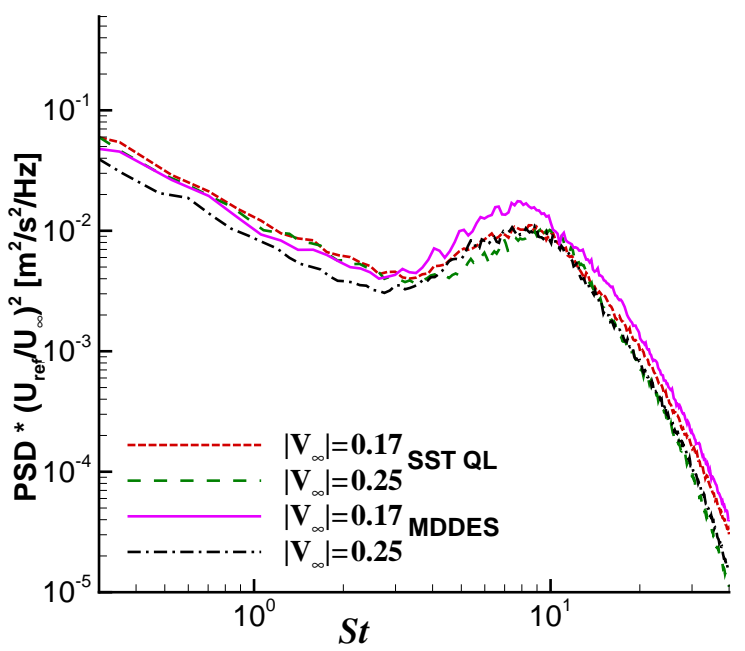

(b) $S / S_{\max }=0.45$

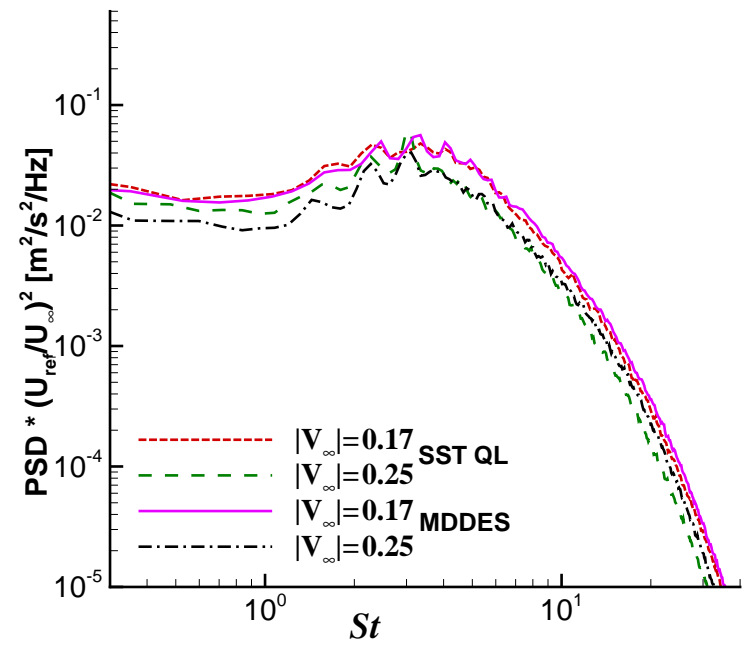

(d) $S / S_{\max }=0.81$

Figure 22. PSD of the $u$ velocities versus Strouhal number at 4 locations along the trajectory of the slat cove shear layer shown in Fig. 4. 


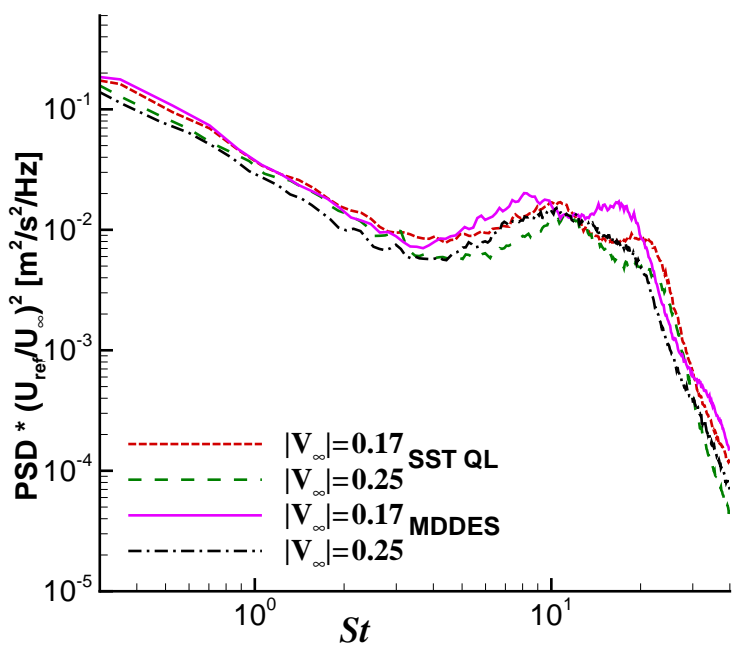

(a) $S / S_{\max }=0.20$

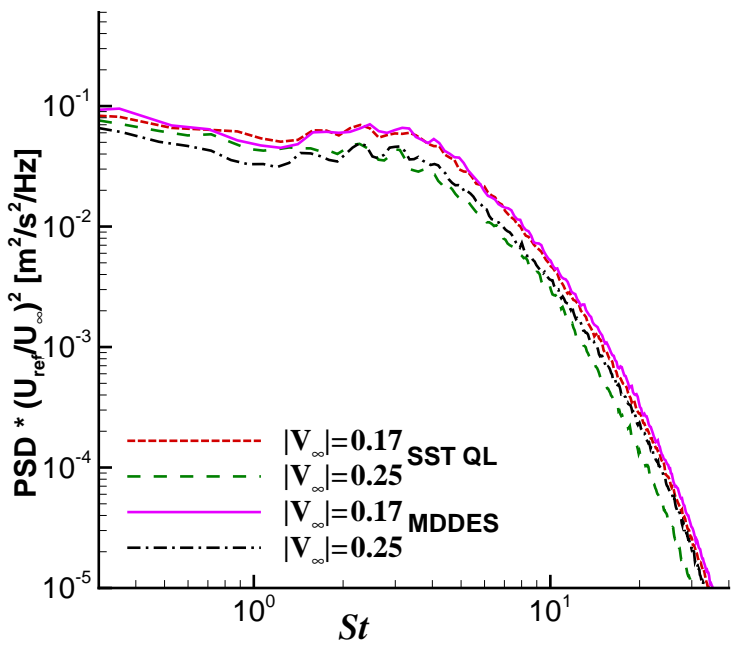

(c) $S / S_{\max }=0.60$

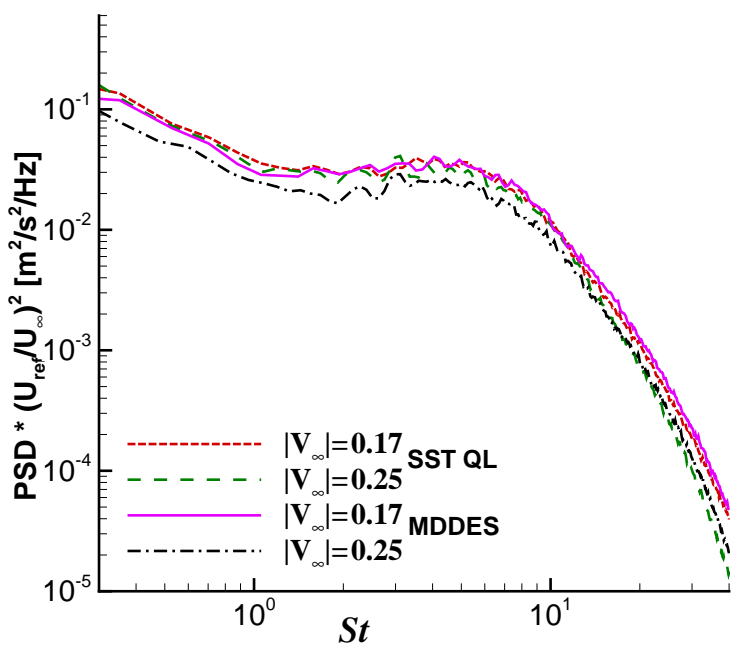

(b) $S / S_{\max }=0.45$

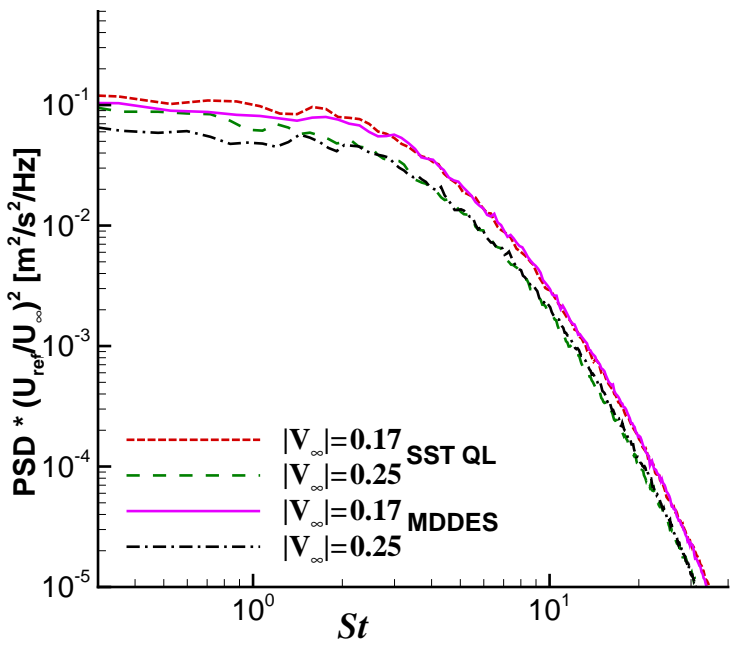

(d) $S / S_{\max }=0.81$

Figure 23. PSD of the $v$ velocities versus Strouhal number at 4 locations along the trajectory of the slat cove shear layer shown in Fig. 4.

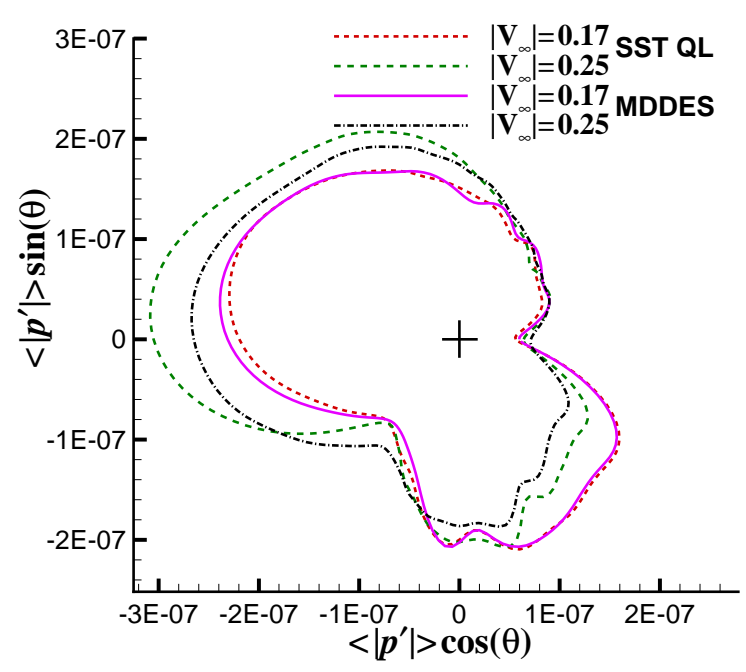

(a) Directivity

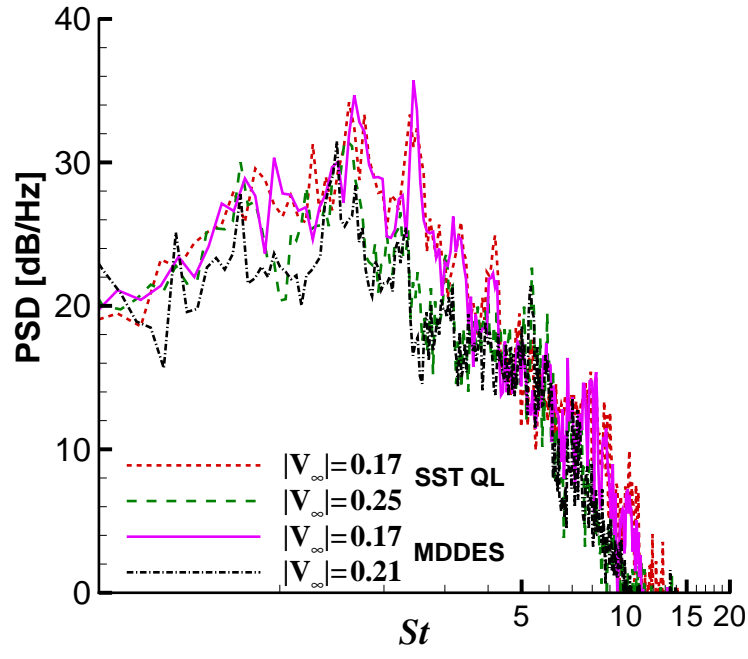

(b) Spectra at $310^{\circ}$

Figure 24. FW-H predictions for observers 10 chords from the slat trailing edge. Directivity scaled assuming $p^{\prime 2} \sim U_{\infty}^{5}$ with $U_{\text {ref }}=0.17$. 